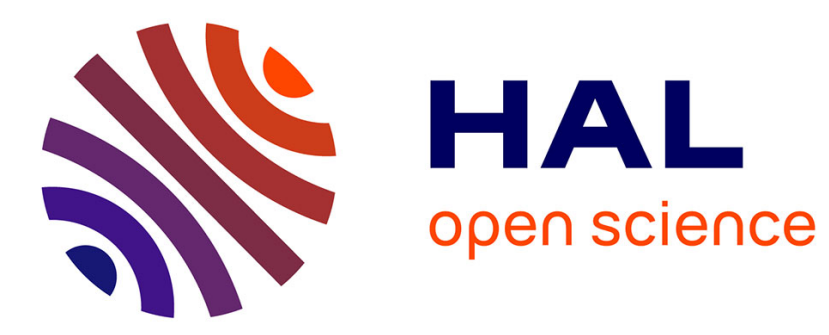

\title{
Cellulose: from biocompatible to bioactive material
}

Julie Credou, Thomas Berthelot

\section{To cite this version:}

Julie Credou, Thomas Berthelot. Cellulose: from biocompatible to bioactive material. Journal of materials chemistry B, 2014, 2, pp.4767-4788. 10.1039/c4tb00431k . hal-01156573

\section{HAL Id: hal-01156573 https://hal.science/hal-01156573}

Submitted on 17 Nov 2015

HAL is a multi-disciplinary open access archive for the deposit and dissemination of scientific research documents, whether they are published or not. The documents may come from teaching and research institutions in France or abroad, or from public or private research centers.
L'archive ouverte pluridisciplinaire HAL, est destinée au dépôt et à la diffusion de documents scientifiques de niveau recherche, publiés ou non, émanant des établissements d'enseignement et de recherche français ou étrangers, des laboratoires publics ou privés. 


\section{Cellulose: from biocompatible to bioactive material}

Cite this: J. Mater. Chem. B, 2014, 2, 4767

Received 18th March 2014 Accepted 8th May 2014

DOI: $10.1039 / c 4 t b 00431 k$

www.rsc.org/MaterialsB

\author{
Julie Credou and Thomas Berthelot*
}

Since the papyri, cellulose has played a significant role in human culture, especially as paper. Nowadays, this ancient product has found new scientific applications in the expanding sector of paper-based technology. Among paper-based devices, paper-based biosensors raise a special interest. The high selectivity of biomolecules for target analytes makes these sensors efficient. Moreover, simple paper-based detection devices do not require hardware or specific technical skill. They are inexpensive, rapid, user-friendly and therefore highly promising for providing resource-limited settings with point-of-care diagnostics. The immobilization of biomolecules onto cellulose is a key step in the development of these sensing devices. Following an overview of cellulose structural features and physicochemical properties, this article reviews current techniques for the immobilization of biomolecules on paper membranes. These procedures are categorized into physical, biological and chemical approaches. There is no universal method for biomolecule immobilization. Thus, for a given paper-based biochip, each strategy can be considered.

\section{Introduction}

Cellulose is the most abundant organic chemical on earth. This natural polymer was first mentioned by the French chemist Anselme Payen in $1838 .^{1}$ He suggested that the cell walls of almost all plants are constructed of the same substance. He described that a resistant fibrous solid remains behind after

CEA Saclay, IRAMIS, NIMBE, LICSEN (Laboratory of Innovation in Surface Chemistry and Nanosciences), F-91191 Gif sur Yvette, France. E-mail: julie.credou@cea.fr; thomas.berthelot@cea.fr; Fax: +33 169084044; Tel: +33 169086588 treatment of various plant tissues with ammonia and acids, and after subsequent extraction with water, alcohol and ether. By elemental analysis, he deduced its molecular formula to be $\mathrm{C}_{6} \mathrm{H}_{10} \mathrm{O}_{5}$. The term "cellulose" was first used one year later in a report of the French Academy of Sciences on Payen's work. ${ }^{2,3}$

The current economic and ecological situations have led to an increasing ecological awareness and a growing will for sustainable technologic and economic development. Thus, scientists are urged to search for environmentally friendly materials and renewable resources. As the main component of



Julie Credou entered the Ecole normale supérieure de Cachan (ENS Cachan) in 2007. She received her $M S c$ degree in Chemistry from ENS Cachan and Paris-Sud University in 2011. She is currently a PhD student in the Laboratory of Innovation in Surface Chemistry and Nanosciences (LICSEN) at the French Alternative Energies and Atomic Energy Commission (CEA) (Saclay, France). Under the supervision of Dr Thomas Berthelot and Dr Hervé Volland, her work focuses on the development of paper-based immunosensors for point-of-care diagnostic applications.

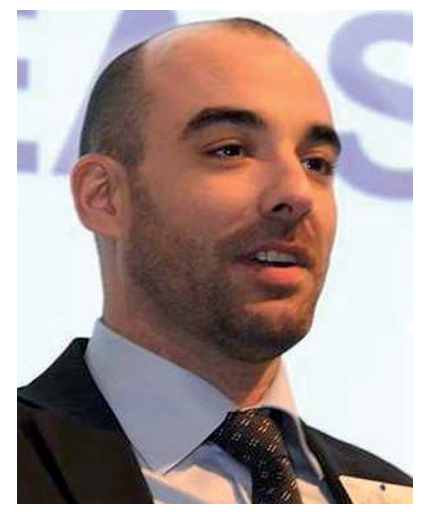

Dr Thomas Berthelot obtained his PhD in Organic Chemistry in 2005 in the Bordeaux I University after interdisciplinary studies at the frontier of Biology and Chemistry. In 2006, he joined the French Alternative Energies and Atomic Energy Commission (CEA) for a postdoctoral fellowship to develop biomimetic polymer membranes for fuel cells. In 2007, he was appointed permanent CEA researcher and he participated in the creation of a surface chemistry start-up (Pegastech SA, France). He currently works at the Laboratory of Innovation in Surface and Nanosciences (LICSEN). His research focuses in NanoMedicine. He is the (co)author of more of than 30 peer review articles in international journals and 24 patents. 
plant skeleton, cellulose is an almost inexhaustible raw material. $^{\mathbf{4}, 2}$ It is therefore a key source of sustainable materials. ${ }^{5}$ Moreover, thanks to its biocompatibility and biodegradability, cellulose is gaining more and more importance and appears as a grade one material. ${ }^{6}$ Apart from its large bioavailability and good biodegradability, cellulose has lots of appealing features. It is rigid, highly crystalline, insoluble in common organic solvents, and therefore an ideal structural engineering material. ${ }^{6}$ With special regard to cellulose paper, its wicking properties enable components to travel by capillarity with no need for any external power source. In addition, its biocompatibility and porosity allow biological compounds to be stored in the paper device. ${ }^{7}$ Besides, cellulose sheets are inexpensive, available in a broad range of thicknesses and well-defined pore sizes, easy to store and handle, and finally safely disposable. ${ }^{8}$

Because of all these features, a new technological sector has developed and has kept growing within the last ten years: paperbased technology. ${ }^{9}$ Paper has attracted scientists' interest since the $19^{\text {th }}$ century. The first urine test strips were developed by the French chemist Jules Maumené in $1850^{\mathbf{1 0}}$ and marketed by the English physiologist George Oliver in 1883. ${ }^{11,12}$ A century later, in 1943, Martin and Synge invented paper chromatography ${ }^{\mathbf{1 3 , 1 4}}$ in order to analyze the amino-acid content of proteins. Contemporaneously, in 1949 Müller and Clegg carried out a study on the preferential elution of a mixture of pigments in a restricted channel designed on paper, ${ }^{15}$ hence laying the technical basis of paper-based microfluidics. Few years later, in 1957, the first paper-based bioassay used an enzyme immobilized onto paper in order to detect glucose in urine. ${ }^{16}$ In 1982, paper-based immunoassays such as dipstick tests or lateral flow immunoassays (LFIAs) were further developed and marketed. ${ }^{17-20}$ They were then extensively employed for point-of-care (POC) diagnostics and pathogen detection, ${ }^{\mathbf{2 1 , 2 2}}$ with diabetes and pregnancy tests being the most famous. ${ }^{23,24}$ Recently, further impetus was given to paper-based microfluidics by Whitesides' research group with the development of threedimensional microfluidic paper analytical devices ( $\mu$ PADs). ${ }^{25}$ This opened the way to many other multiplex paper-based analytical devices. ${ }^{26-33}$ Meanwhile, the Sentinel Bioactive Paper Network was formed in Canada in $2005,{ }^{34}$ thereby setting the paper-based bioassay as a whole new section of biosensing research. Thus, cellulose is not anymore the "fibrous solid that remains behind", it is a material platform used to create novel devices for diagnostics, microfluidics, and electronics.

According to the World Health Organization (WHO), diagnostic devices for developing countries should be ASSURED: Affordable, Sensitive, Specific, User-friendly, Rapid and robust, Equipment free and Deliverable to end-users. ${ }^{21,35,36}$ The aforementioned appealing characteristics of cellulose therefore give paper-based devices a great potential to comply with these requirements and to improve point-of-care (POC) testing. Besides, it would be only logical for this natural biopolymer which is available anywhere to be readily available for use everywhere it is needed.

Among paper-based devices, bioactive papers raise a special interest because they can be useful in many fields including clinical diagnosis ${ }^{28,35,37,38}$ and environmental monitoring. ${ }^{29,39-41}$
They are the main materials for developing paper-based pointof-care (POC) diagnostic devices and therefore will be the main subject of this paper. Thus, this review focuses on the way to develop a bioactive material from the biocompatible cellulose material. We will therefore concentrate on cellulose as a support for biomolecule immobilization. After describing the related cellulose features such as fiber physicochemical properties, we will then present the existing strategies for biomolecule immobilization onto pure cellulose.

\section{Cellulose: a biocompatible material}

According to IUPAC Recommendations 2012, biocompatibility is defined as the ability to be in contact with a living system without producing an adverse effect. ${ }^{42}$ As a ubiquitous natural biopolymer, cellulose is by definition a biocompatible material.

\subsection{Features}

2.1.1. Structure. As a polymer, cellulose is a macromolecule and therefore needs to be defined on three structural levels: molecular, supramolecular and morphological levels. On the molecular level, cellulose is described as a single macromolecule. Its chemical constitution, its reactive sites and its potential intramolecular interactions are considered. On the supramolecular level, cellulose is described as a pack of several macromolecules interacting and ordering each other. Importance is attached to aggregation phenomena, crystalline organization and fibrils formation. On the morphological level, structural entities formed by cellulose are described. Layouts made of different supramolecular arrangements are studied.

2.1.1.1. Molecular structure. Cellulose possesses the simplest structure among polysaccharides since it is composed of a unique monomer: glucose under its $\beta$-D-glucopyranose form (Fig. 1). Cellulose is a polydisperse, linear, syndiotactic polymer. Glucose molecules are covalently linked through acetal functions between the equatorial hydroxyl groups of $\mathrm{C} 4$ and the $\mathrm{C} 1$ carbon atoms. This succession of glycosidically linked anhydroglucose units (AGUs) results in a long chain $\beta$-1,4-glucan. ${ }^{2,3,6}$

The chain length, also called the degree of polymerization (DP), is expressed as the number of AGUs constituting the chain. The average DP value not only depends on the origin of the raw material, but also on the potential extraction treatments. For example, cellulose from wood pulp has average DP values around 300 and 1700 . In the case of cotton and other

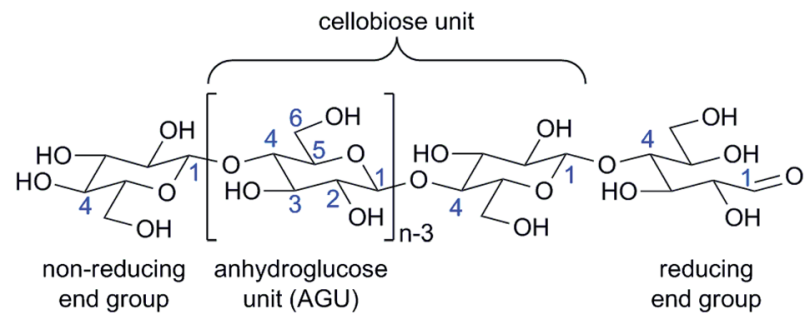

Fig. 1 Cellulose molecular structure ( $n=\mathrm{DP}$, degree of polymerization). 
plant fibers, DP values range from 800 to 10000 . Similar values are reported in bacterial cellulose. ${ }^{2}$

Each AGU ring adopts the ${ }^{4} C_{1}$ chair conformation (Fig. 2). Since the ring substituents and the glycosidic bonds are all in the ring plane (equatorial), this conformation ensures the less van der Waals and steric repulsion between them. It is the most stable conformation and thus the thermodynamically preferred conformation. To comply with this conformation and to accommodate the preferred bond angles of the acetal bridges, adjacent AGUs have their mean planes at an angle of $180^{\circ}$ to each other. Hence, two adjacent AGUs define the disaccharide cellobiose (Fig. 1)., ${ }^{2,6}$

Furthermore, both ends of the cellulose chain are different (Fig. 1). At one end, the glucose unit is still a closed ring and displays an original $\mathrm{C} 4-\mathrm{OH}$ group. This is the non-reducing end. At the other end, both pyranose ring structures (cyclic hemiacetal) displaying an original $\mathrm{C} 1-\mathrm{OH}$ group and an aldehyde structure are in equilibrium (Fig. 3), thereby conferring reducing properties. This is the reducing end.

As a result of the glucose structure, cellulose contains a large amount of free hydroxyl groups located at the C2, C3, and C6 atoms. These hydroxyl groups, together with the oxygen atoms of both the pyranose ring and the glycosidic bond, form an extensive hydrogen bond network. This network is composed of both intra- and intermolecular hydrogen bonds. While the intramolecular hydrogen bonds are partly responsible for the linear integrity and rigidity of the polymer chain, intermolecular hydrogen bonds result in crystalline structures and other supramolecular arrangements. The main intramolecular hydrogen bond is the $\mathrm{O} 3 \mathrm{H}-\mathrm{O}^{\prime}$ bond; it is shared by most allomorphs. $\mathrm{O} 2 \mathrm{H}-\mathrm{O}^{\prime}$ hydrogen bonds also occur in some allomorphs. Both are shown in Fig. $4^{6,43}$

2.1.1.2. Supramolecular structure. Pure cellulose exists in several allomorphic forms. Native cellulose I crystallized simultaneously in two forms in which chains are packed in parallel: $\mathrm{I}_{\alpha}$ and $\mathrm{I}_{\beta}$. On the other hand, chains in regenerated or mercerized cellulose II are arranged antiparallel. Treatment of cellulose I and II with liquid ammonia leads to cellulose III $_{1}$ and $\mathrm{III}_{2}$, respectively, and each allomorph may be converted back to

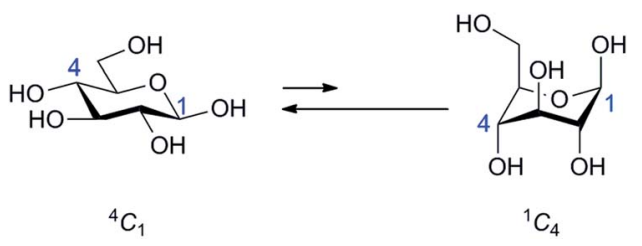

Fig. $2 \beta$-D-glucopyranose conformations.

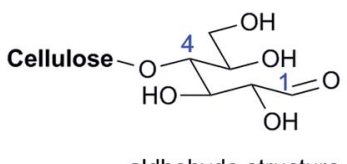

aldhehyde structure

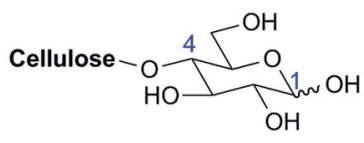

cyclic hemiacetal structure
Fig. 3 Reducing end equilibrium.

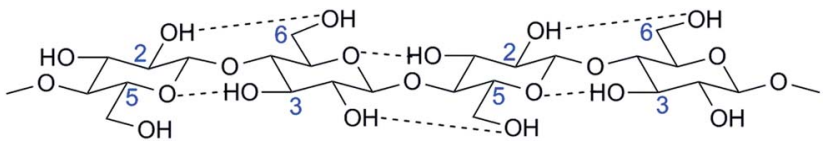

Fig. 4 Intramolecular hydrogen bonding in cellulose.

the starting cellulose material. Heat treatment of cellulose III $_{1}$ and $\mathrm{III}_{2}$ leads to cellulose $\mathrm{IV}_{1}$ and $\mathrm{IV}_{2}$, respectively, which can also be converted back to the original cellulose. ${ }^{44}$

With respect to cellulose $\mathrm{I}$, the $\mathrm{I}_{\alpha} / \mathrm{I}_{\beta}$ ratio depends on the origin of the cellulose. The $\mathrm{I}_{\beta}$ form prevails in woody plants and cotton whereas the $I_{\alpha}$ form dominates in primitive organisms such as bacteria or algae. ${ }^{3,45}$ Cellulose $\mathrm{I}_{\alpha}$ has a triclinic unit cell including one chain whereas $\mathrm{I}_{\beta}$ has a monoclinic unit cell including two parallel chains. The $\mathrm{I}_{\beta}$ form is thermodynamically more stable than the $\mathrm{I}_{\alpha}$ form.

Cellulose II is the most stable among cellulose crystal structures. This allomorph can be produced from cellulose I by mercerization (treatment with aqueous sodium hydroxide) or by dissolution and following precipitation (regeneration of a crystalline form of cellulose). This transformation is considered to be irreversible. ${ }^{43}$ Cellulose II has a monoclinic unit cell which includes two antiparallel chains. ${ }^{2}$

As stated above, intermolecular hydrogen bonds are greatly responsible for the supramolecular structure of cellulose. They make the chains group together in a highly ordered structure. Cellulose I and II differ by their inter- and intramolecular hydrogen bonds, resulting in different packings: parallel and antiparallel, respectively (Fig. 5). The main intramolecular $\mathrm{O} 3 \mathrm{H}-\mathrm{O5}^{\prime}$ hydrogen bond is shared by both polymorphs. The intramolecular $\mathrm{O} 2 \mathrm{H}-\mathrm{O}^{\prime}$ hydrogen bond only occurs in cellulose I (both $\mathrm{I}_{\alpha}$ and $\mathrm{I}_{\beta}$ ). Cellulose I has $\mathrm{O} 6 \mathrm{H}-\mathrm{O}^{\prime \prime}$ intermolecular hydrogen bonds whereas cellulose II has $\mathrm{O} 6 \mathrm{H}-\mathrm{O} 2^{\prime \prime}$ intermolecular hydrogen bonds. ${ }^{2,3}$

The chains are usually longer than the crystalline regions. As a consequence, one chain can run from one crystalline region to another, passing through amorphous areas, and thereby holding the ordered regions together. ${ }^{\mathbf{4 6 , 4 7}}$ The intermolecular hydrogen bonds in the crystalline regions are strong, hence ensuring the resultant fiber is strong as well and insoluble in most solvents. They also prevent cellulose from melting. In the amorphous regions, the intermolecular hydrogen bonds are fewer and looser, enabling the chains to form hydrogen bonds with other molecules such as water. This imparts macromolecular cellulose its hygroscopic and hydrophilic features. Thus, cellulose swells but does not dissolve in water. ${ }^{46}$

Cellulose fibers have amorphous and crystalline regions. Their ratio, or crystallinity rate, depends on the origin of cellulose. Cotton, flax, ramie and sisal have high degrees of crystallinity which range from $65 \%$ to $70 \%$ whereas crystallinity of regenerated cellulose only ranges from $35 \%$ to $40 \%{ }^{6}$

2.1.1.3. Morphological structure. Gathering different supramolecular arrangements of cellulose (crystalline and amorphous areas) results in fibrillar elements of nanometer-scale diameters and micrometer-scale lengths. ${ }^{\mathbf{4 3 4}}$ These are called fibrils or microfibrils. Assembling these microfibrils together 



Fig. 5 Supramolecular distinction between cellulose I and cellulose II lies in inter- and intramolecular hydrogen bonds.

results in macrofibrils of micrometer-scale diameters and millimeter-scale lengths. Micro- and macrofibrils represent the building block of the cellulose fiber cell wall.

Plant fibers consist of different cell-wall layers (primary and secondary walls, middle lamellae) surrounding the central lumen. The lumen takes part in the water uptake behavior of plant fibers. The primary cell wall must be capable of growth and therefore be flexible. The secondary cell wall has to be rigid in order to avoid buckling. ${ }^{49}$ The secondary cell wall accounts for approximately $80 \%$ of the entire cell wall thickness. It therefore determines the mechanical properties of the fiber. ${ }^{46,50}$ The secondary cell wall is made up of three layers. The thickest is the middle layer which consists of a series of helically wound cellular microfibrils. The angle between the fiber axis and the microfibrils is called the microfibrillar angle. Its average value varies from one fiber to another. Features of each cell-wall layer are provided by the particular fibrillar layout and the amount of other components such as lignin (see next Section 2.1.2). ${ }^{6,43}$

Thus, cellulose forms the basic material of all plant fibers. Fig. 6 presents how cellulose molecules and resultant fibrils take part in the cell walls of plant fibers.

2.1.2. Bioavailability and fiber components. Cellulose is the most abundant form of worldwide biomass. ${ }^{51}$ It is the main material of plant cell walls, and therefore the most important skeletal component in plants. Apart from plants which are the dominant cellulose suppliers, cellulose is also produced by algae, bacteria and fungi. Thus, about $1.5 \times 10^{12}$ tons are biosynthesized annually, thereby leading cellulose to be considered an almost inexhaustible polymeric raw material. ${ }^{2}$

The conventional sources of cellulose are wood pulp and cotton linters. ${ }^{6}$ The seed hairs of the cotton plant provide cellulose in almost the pure form. In contrast, the cell wall of woody plants provides a composite material mainly made of cellulose, hemicelluloses and lignin. It may also contain pectin, extractives such as waxes, or even proteins. ${ }^{2, \mathbf{4 , 6}}$

Hemicelluloses are water soluble polysaccharides of low degree of polymerization (100-200). While cellulose is a linear homopolymer of glucose, hemicelluloses are branched heteropolymers made of many different sugars such as glucose, mannose, galactose, xylose and arabinose (see the most abundant sugar monomers in Fig. 7). Sugar ratio changes from plant to plant. ${ }^{3,6}$

As for lignin, this is a non-linear polymer made of phenylpropanoid units. Its whole structure has not been fully resolved yet (see monomers and a representative fragment structure in Fig. 8) and its monomer ratio changes from plant to plant as well. While cellulose is the main building block of wood, lignin is the cement which binds the wood cells together. It is covalently linked to hemicellulose and thus crosslinks polysaccharides, thereby giving rigidity to the plant. ${ }^{6,52}$ In addition, lignin plays a key role in controlling the water content within the cell wall and conducting water in plant stems. Whereas polysaccharides of plant cell walls are highly hydrophilic and thus permeable to water, lignin contains both hydrophilic and

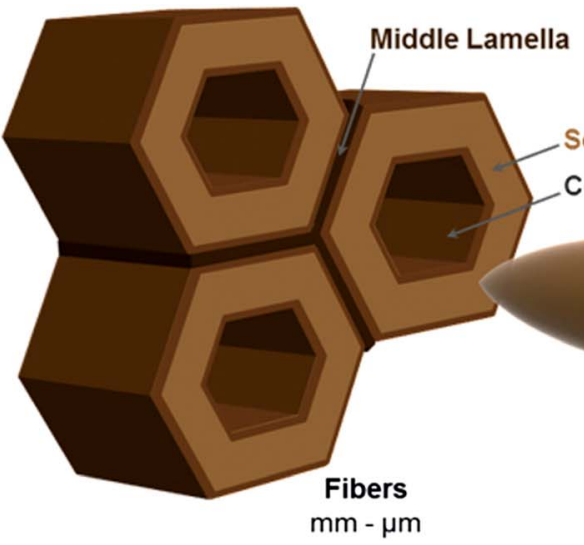

Secondary Wall Central Lumen
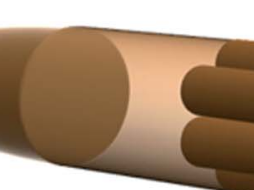

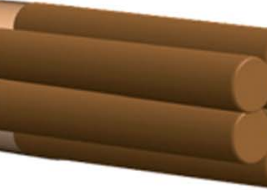

Fibrils

$\mu \mathrm{m}-\mathrm{nm}$

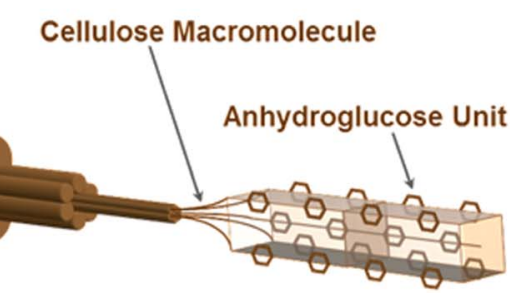

Crystal Structure A

Fig. 6 Contribution of cellulose to the cell wall of plant fiber. 

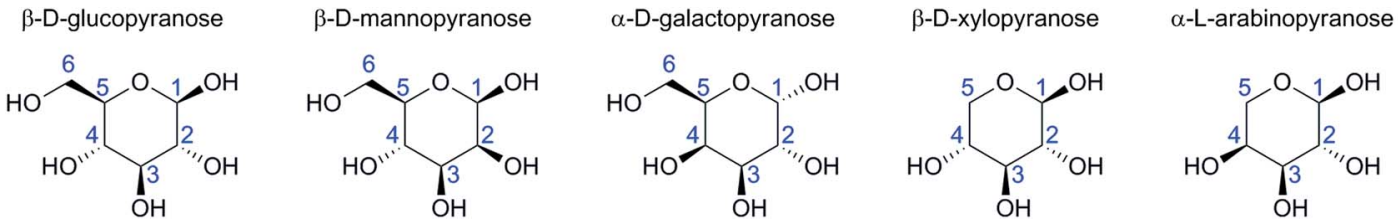

$\alpha$-L-arabinofuranose

Fig. 7 The most abundant monomers of wood hemicelluloses.

(a)<smiles>OC/C=C/c1ccc(O)cc1</smiles>

sinapyl alcohol<smiles>COc1cc(/C=C/CO)cc(OC)c1O</smiles>

(b)

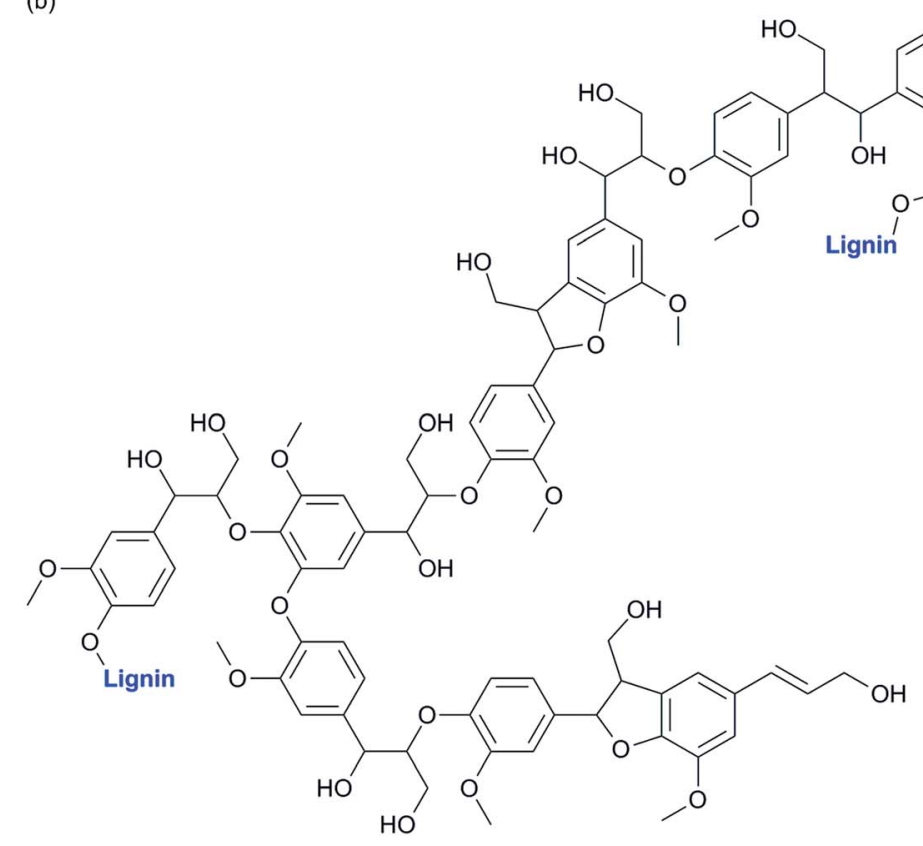

Fig. 8 (a) The three monomers of lignin. (b) A representative fragment of the lignin structure.

hydrophobic groups which make it much less hydrophilic. Since lignin is crosslinked between polysaccharides, it stands in the way and prevents water absorption into the cell walls, thereby enabling water driving. Finally, because of its aromatic nature, lignin is mainly responsible for the color in wood. This feature appears as a drawback regarding papermaking industry. That is why processes such as pulping and bleaching have been developed in order to remove lignin from the wood matrix (see Section 2.3.1). ${ }^{3}$

Pectins are complex heteropolysaccharides mainly composed of $(1 \rightarrow 4)$ - $\alpha$-D-galacturonic acid residues. The most abundant pectic polysaccharide is a linear homopolymer of 1,4 -linked- $\alpha$-galacturonic acid called homogalacturonan. The other pectic polysaccharides are made of a backbone of 1,4-linked- $\alpha$-galacturonic acid residues decorated with side branches consisting of different sugars and linkers. ${ }^{53}$ These backbone and sugars are presented in Fig. 9. The amount, structure and composition of pectins vary from plant to plant, but also within a plant depending on the location and the age. Pectins are soluble in alkaline water. They provide flexibility to plants. They also play a role in plant growth, development, morphogenesis, defense, cell-cell adhesion, wall structure, signaling, cell expansion, wall porosity, binding of ions, growth factors and enzymes, pollen tube growth, seed hydration, leaf abscission, and fruit development. ${ }^{6,53}$

The protein content of wood cells is usually low (less than $1 \%)$, but can be higher in some grasses. The encountered proteins are structural proteins such as hydroxyproline-rich glycoproteins, glycine-rich proteins and proline-rich proteins. ${ }^{4}$

The extractives are all substances resulting from wood extraction processes that are not an integral part of the cellular structure. They are made soluble by extraction processes and can be removed by dissolution in solvents that do not dissolve cellulose such as water, ether, alcohol or benzene. The extractive content of the wood material is about 2 to $5 \%{ }^{3}$ Extractives can be chemicals such as fats, fatty acids, fatty alcohols, phenols, terpenes, steroids, resin acids, rosin, waxes, etc. These chemicals may be encountered as monomers, dimers or polymers. ${ }^{4}$ Waxy layers contribute to render the fiber impermeable to water.

All these alien substances associated with the cellulose matrix are important and should be kept in mind when further dealing with cellulose chemical modifications. Indeed, they occur naturally in cellulose-containing materials and their ratio depends on the source of the cellulose (see distribution of these additives within some typical cellulose-containing materials in 
(a)

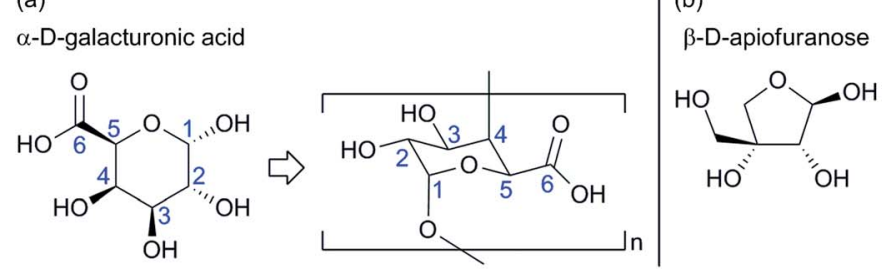

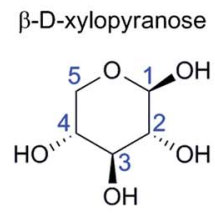

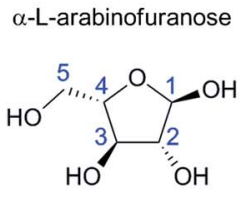

$\beta$-D-galactopyranose

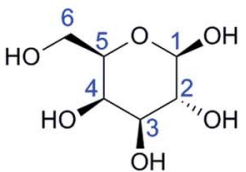

Fig. 9 (a) Galacturonic backbone of pectins. (b) The most abundant sugars of pectins.

Table 1$).{ }^{43}$ Thus, depending on the source of the cellulose material and the effectiveness of the purification process, these compounds may occur in the final cellulose product and eventually interfere with cellulose chemical modification.

2.1.3. Biodegradability. The increasing ecological awareness and the growing will for sustainable technologic and economic development have stimulated the search for environmentally friendly materials. In particular, the waste disposal problem has to be addressed quickly. These trends have tempted a large part of scientists to search for materials that can be easily biodegraded or bioassimilated. ${ }^{6}$ To these scientists, cellulose therefore appears as a grade one material.

First of all, it is important to notice that cellulose is digestible by all grass-, leave- and wood-eating species, such as cows, pandas, beetle larvae and termites. This ability results from a lignocellulose-degrading symbiotic ecosystem located in their digestive tract. This ecosystem consists of bacteria or protozoa depending on the species which produce enzymes dedicated to break down cellulose. ${ }^{54-57}$ The main glycolytic enzymes involved in the biological conversion of cellulose to glucose are endoglucanases, cellobiohydrolases and $\beta$-glucosidases. While endoglucanases randomly hydrolyze $1,4-\beta$ bonds along the cellulose chains, cellobiohydrolases split off cellobiosyl units from non-reducing end groups and $\beta$-glucosidases cleave glucosyl units from nonreducing end groups. ${ }^{54}$ There are also other enzymes which are dedicated to hydrolyze the other compounds from plant cell walls such as hemicellulase and xylan 1,4- $\beta$-xylosidase. ${ }^{55,57}$

Some fungi are also able to break down cellulose. Actually, fungi are among the most degradative organisms inducing biodeterioration of paper-based items. ${ }^{58}$ Many fungal species

Table 1 Chemical composition of some typical cellulose-containing materials

\begin{tabular}{lllll}
\hline & \multicolumn{2}{l}{ Composition $(\%)$} & \\
\cline { 2 - 5 } Source & Cellulose & Hemicellulose & Lignin & Extract \\
\hline Cotton & 95 & 2 & 1 & 0.4 \\
Flax (retted) & 71 & 21 & 2 & 6 \\
Jute & 71 & 14 & 13 & 2 \\
Hemp & 70 & 22 & 6 & 2 \\
Corn cobs & 45 & 35 & 15 & 5 \\
Hardwood & $43-47$ & $25-35$ & $16-24$ & $2-8$ \\
Softwood & $40-44$ & $25-29$ & $25-31$ & $1-5$ \\
Bagasse & 40 & 30 & 20 & 10 \\
Coir & $32-43$ & $10-20$ & $43-49$ & 4
\end{tabular}

(over 200) are involved in paper biodeterioration. The effectiveness and the rate of the deterioration process are affected by environmental conditions (e.g. temperature, humidity, light). ${ }^{\mathbf{5 9 , 6 0}}$ Their main strength is that a single cell is enough to induce proliferation over most solid surfaces. Moreover, they can be "sleeping" for years as spores and then be reactivated under a certain set of conditions. ${ }^{61}$

Because of its sustainability, biocompatibility and biodegradability, cellulose is a material of growing interest to the current economic and ecological climate.

\subsection{Physicochemical properties}

2.2.1. Mechanical properties: "the branch bends but does not break". As stated above, plant cell walls are responsible for the proper growth and structural integrity of plants. As their main component, cellulose plays a key role in the shape and mechanical strength of living plants. ${ }^{\mathbf{4 9 , 6 2}}$

Yet, the term strength may not make much sense by itself. In the informal language strength is synonymous with solidity, firmness or rigidity. But actually, the mechanical definition of the strength of a material mainly takes two properties into consideration: (i) the stiffness of the material, which is measured by its Young's modulus and (ii) the tensile strength (or ultimate tensile strength) of the material, which is the maximum stress that a material can withstand while being stretched before breaking. Considering that "the branch bends but does not break" means that plant fibers have low Young's modulus but high tensile strength. The main asset of cellulose fiber is therefore its resilience.

The tensile strength and Young's modulus of commercially important fibers are detailed in Table $2 .^{\mathbf{5 0 , 6 3 , 6 4}}$ Cellulose fibers have relatively high strength (tensile strength), medium stiffness (Young's modulus), and low density. Considering their lower density, the natural fibers compare quite well with glass fiber, but are not as strong as carbon fibers or Kevlar.

Mechanical tests of whole plant or solid wood (macroscopic scale) provide information about their elementary mechanical properties which are partly influenced by tissue interactions. Additionally, the tensile testing of single cellulose fiber provides more information about the effects of the cell-wall structure on the mechanical properties of plant fiber. ${ }^{50}$ The tensile strength of elementary fibers is about $1500 \mathrm{MPa}$. Their Young's modulus depends on their diameter. It ranges from $39 \mathrm{GPa}$ to $78 \mathrm{GPa}$ for fibers having diameters from $35 \mu \mathrm{m}$ to $5 \mu \mathrm{m}$, respectively. From bulk natural fibers to cellulose molecules, the elastic modulus 
Table 2 Mechanical properties of natural fibers compared to socalled "strong materials"

\begin{tabular}{|c|c|c|c|c|}
\hline Fiber & $\begin{array}{l}\text { Density } \\
\left(\mathrm{g} \mathrm{cm}^{-3}\right)\end{array}$ & $\begin{array}{l}\text { Tensile } \\
\text { strength } \\
(\mathrm{MPa})\end{array}$ & $\begin{array}{l}\text { Young's } \\
\text { modulus } \\
(\mathrm{GPa})\end{array}$ & $\begin{array}{l}\text { Elongation } \\
\text { at break } \\
(\%)\end{array}$ \\
\hline Cotton & $1.5-1.6$ & $287-597$ & $5.5-12.6$ & $7.0-8.0$ \\
\hline $\begin{array}{l}\text { Wood fibers } \\
\text { (spruce latewood) }\end{array}$ & - & $530-675$ & $20.8-60.1$ & - \\
\hline Rayon & 1.6 & 500 & 40 & 1.25 \\
\hline Flax & 1.5 & 351 & 28.5 & 2.5 \\
\hline Hemp & 1.48 & 820 & 29.6 & 3.5 \\
\hline Jute & 1.5 & 579 & 26.2 & 1.5 \\
\hline Viscose (cord) & - & 593 & 11.0 & 11.4 \\
\hline Aramid (Kevlar 49) & 1.45 & 2900 & 130 & 2.5 \\
\hline Carbon (NM) & 1.86 & 2700 & 380 & 0.7 \\
\hline E-glass & 2.54 & 2200 & 70 & 3.1 \\
\hline Portland cement concrete & $2.2-2.4$ & $2-5$ & $14-41$ & - \\
\hline
\end{tabular}

values range as follows: $10 \mathrm{GPa}$ for wood bulk fiber, $40 \mathrm{GPa}$ for cellulose fiber (after pulping process), $70 \mathrm{GPa}$ for microfibril, and $250 \mathrm{GPa}$ for the cellulose chain (from theoretical calculations).$^{46}$ In other words: "the smaller, the stronger".

2.2.2. Chemical reactivity: functional cellulose derivatives. According to the molecular structure of cellulose (Fig. 1), hydroxyl groups in glucose units are responsible for its chemical activity. Under heterogeneous conditions their reactivity may be affected by their inherent chemical reactivity and by steric hindrance stemming either from the reagent or from the supramolecular structure of cellulose itself. ${ }^{47}$ Therefore, the accessibility and reactivity of the hydroxyl groups depend on their degree of involvement in the supramolecular structure. In other words, it depends on their involvement in the hydrogen bond network. Intramolecular hydrogen bonding between adjacent AGUs particularly affects the reactivity of the C3 hydroxyl group, which hydrogen binds strongly to the ring oxygen on adjacent AGUs (O3H-O5' hydrogen bond) whatever the allomorph and is therefore not available to react. ${ }^{6}$ In contrast, C2 and C6 hydroxyl groups have multiple and variable options to hydrogen bind, what may result in a lower statistical involvement in the hydrogen bond network, and thus a higher reactivity. ${ }^{3}$ Among the three hydroxyl groups in each glucose residue, the one at 6-position (primary alcohol) is described as the most reactive site, far more than hydroxyl groups at 2- and 3positions (secondary alcohols). However, the relative reactivity of the hydroxyl groups can be generally expressed in the following order: $\mathrm{OH}-\mathrm{C} 6 \gg \mathrm{OH}-\mathrm{C} 2>\mathrm{OH}-\mathrm{C} 3 .{ }^{47}$

The accessibility to these reactive hydroxyl groups also depends on the crystalline structure of the fiber. Chemical reagents cannot penetrate the crystalline regions but only the amorphous area (see Section 2.1.1.2). ${ }^{47}$ Activation treatments can enhance the accessibility and the reactivity of cellulose for subsequent reactions. These treatments implement methods such as (i) widening surface cannulae, internal pores and interfibrillar interstices, (ii) disrupting fibrillar aggregation, in order to make available additional areas, (iii) troubling the crystalline order, and (iv) modifying the crystal form and therefore changing the hydrogen bonding scheme and the relative availability of the reactive hydroxyls. Among all activation treatments, swelling is the most frequently used procedure and aqueous sodium hydroxide solution is the most common swelling agent. Swelling agents usually penetrate the ordered regions, and split some hydrogen intermolecular bonds. After alkali treatment (such as mercerization), the structure of native cellulose fibers stays fibrillar but the degree of disorder increases, and so does the accessibility. ${ }^{47}$

When cellulose chemically reacts through its hydroxyl groups, the average number of hydroxyl groups per glucose unit that have been substituted defines the degree of substitution (DS) of the cellulose derivatives. Thus, its value ranges from 0 to 3. Because of the relative reactivity and accessibility of the hydroxyl groups, this value is often lower than two, though. Besides, it is not desirable to have all of these hydroxyl groups react in order to keep the structure cohesion and integrity. ${ }^{65}$ Considering that the DS value is often between 0 and $1.5,{ }^{66}$ it is laborious to determine if we are only grafting small molecules onto cellulose. ${ }^{65}$

The ways used to modify the chemical composition of synthetic polymers cannot be applied to natural cellulose because regarding cellulose these features are determined by biosynthesis. Chemical modifications have to be conducted on the whole cellulose polymer. Though, introducing functional groups in the final polymer is a way around the problem. These functional groups may impart new properties to the cellulose without destroying its many appealing intrinsic properties. ${ }^{47}$

Many approaches to cellulose functionalization already exist, ${ }^{67}$ and many others are under development. ${ }^{8,68,69}$ This review focuses on cellulose as a support for biomolecule immobilization and its use for diagnostic devices. Therefore, not all the chemical modifications of cellulose will be presented here. Instead we will concentrate on the chemical modifications which play a role in biomolecule immobilization (see Section 3).

2.2.2.1. Oxidation. Carbonyl and carboxyl groups are very useful for biomolecule immobilization since they can react with primary amines from biomolecules to form imine and amide bonds, respectively (see Section 3.3.2). Carbonyl groups are already present at the reducing end of cellulose chains. Additional carbonyl and carboxyl groups may stem from extraction and purification processes. ${ }^{2}$ Yet, those are not sufficient for functionalization and biomolecule immobilization purposes. Therefore, more carbonyl or carboxyl groups would be obtained by oxidation of the hydroxyl groups from the cellulose. Depending on the experimental conditions, the oxidation may be accompanied by the opening of the pyranose ring (Fig. 10). ${ }^{70}$

The most used method of forming carbonyl groups onto the cellulose skeleton is periodate oxidation. Secondary alcohol groups of the glucose units $(\mathrm{OH}-\mathrm{C} 2$ and $\mathrm{OH}-\mathrm{C} 3)$ are oxidized into the corresponding aldehydes by means of sodium periodate $\left(\mathrm{NaIO}_{4}\right)^{40,71,72}$ This method results in the opening of the pyranose ring by cleavage of the C2-C3 bond (Fig. 10b). Hence, the cellulose structure is locally affected. Depending on the oxidation rate, this may disrupt the linearity of the chain and the supramolecular arrangement to a certain extent. 
(a)
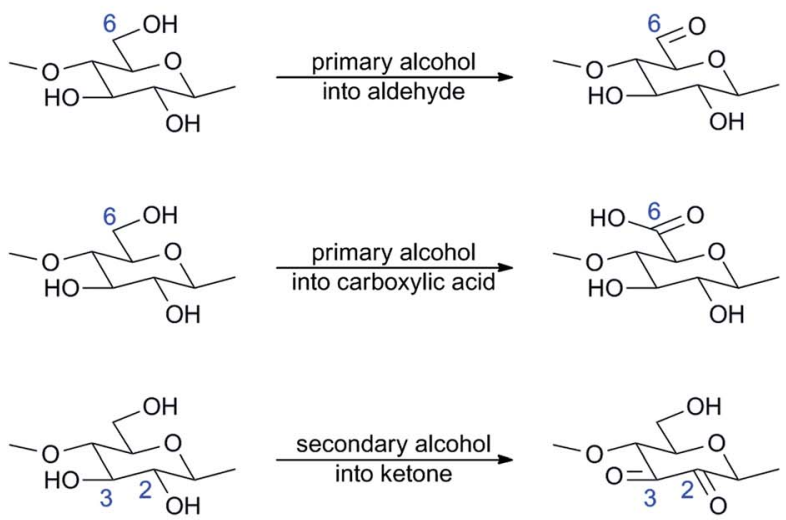

(b)
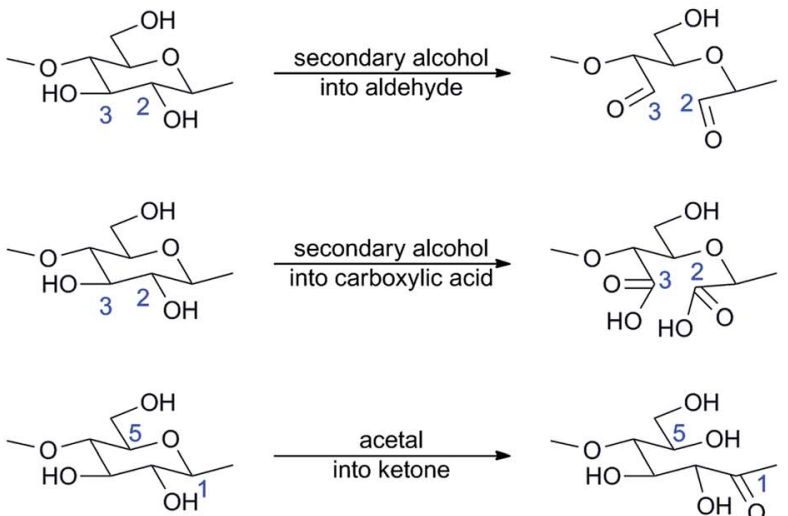

Fig. 10 Main oxidation reactions of cellulose (a) without ring opening and (b) with ring opening.

The usual method of forming carboxyl groups onto the cellulose chain is TEMPO-mediated oxidation. Primary alcohol groups from cellulose $(\mathrm{OH}-\mathrm{C} 6)$ are oxidized into the corresponding carboxylic acids by means of sodium bromide ( $\mathrm{NaBr}$ ), sodium hypochlorite $(\mathrm{NaClO})$ and (2,2,6,6-tetramethyl-piperidin-1-yl)oxyl free radical (TEMPO). ${ }^{73-75}$ In this manner, the pyranose ring is not affected by the process and cellulose keeps its structural integrity (Fig. 10a).

2.2.2.2. Amination. Amination of cellulose was used to covalently bind nitrilotriacetic acid (NTA) onto a cellulose film. ${ }^{76}$ After loading these films with nickel cations $\left(\mathrm{Ni}^{2+}\right)$, it is therefore possible to immobilize His-tagged proteins by bioaffinity attachment and develop biosensors or purification systems (see Section 3.2.4).

The amination process implements a complex procedure since usually both cellulose and amino compound added need to be activated before they can react with each other. However, the synthesis of the NTA-modified cellulose was achieved in two main steps: (i) the activation of the primary hydroxyl group from cellulose (OH-C6), and (ii) the $\mathrm{S}_{\mathrm{N}} 2$ nucleophilic substitution of this activated hydroxyl by an activated $\mathrm{NH}_{2}$-terminal NTA derivative (amination process). Fig. 11 illustrates the amination process resulting in nitrilotriacetic acid (NTA)-modified aminocellulose.

First, hydroxyl groups were activated by tosylation. Cellulose was dissolved in a solution of lithium chloride in $\mathrm{N}, \mathrm{N}$-dimethylacetamide (DMA/LiCl) which is the most important solvent system for cellulose in organic synthesis. ${ }^{2}$ Tosyl chloride (Ts-Cl) was added, together with triethylamine $\left(\mathrm{Et}_{3} \mathrm{~N}\right)$. The average DS value for the tosylation step was $1.45 .^{76}$ On the other hand, the $\mathrm{NH}_{2}$-terminal NTA derivative was activated by persilylation with trimethylsilyl chloride (TMS-Cl) in toluene in the presence of triethylamine. This activated NTA derivative finally reacted with the cellulose tosylate in a DMSO/toluene mixture $\left(\mathrm{S}_{\mathrm{N}} 2\right)$. This amination procedure resulted in NTA-cellulose. The average DS value for the amination reaction was $0.45 .^{76}$

2.2.2.3. Esterification and etherification. Cellulose esters and cellulose ethers are the most important technical derivatives of cellulose. ${ }^{2}$ They find their applications in many industrial sectors including coatings, pharmaceuticals, foodstuffs and cosmetics (Table 3). ${ }^{47,69,77}$

With regard to biomolecule immobilization, cellulose nitrate (also named nitrocellulose) is the most important cellulose derivative. Biomolecules strongly adsorb to nitrocellulose through a combination of electrostatic, hydrogen, and hydrophobic forces. ${ }^{20}$ It is therefore the reference material for performing lateral flow immunoassay (LFIA) ${ }^{18-20,78}$ (see Section 2.3.2). Cellulose nitrate is formed by esterification of hydroxyl groups from cellulose (primary or secondary) with nitric acid $\left(\mathrm{HNO}_{3}\right)$ in the presence of sulfuric acid $\left(\mathrm{H}_{2} \mathrm{SO}_{4}\right)$, phosphoric acid $\left(\mathrm{H}_{3} \mathrm{PO}_{4}\right)$ or acetic acid $\left(\mathrm{CH}_{3} \mathrm{COOH}\right)$ (see Fig. 12$){ }^{47,67}$

Carboxymethyl cellulose (CMC) is another important cellulose derivative used in biomolecule immobilization. It is often coated and strongly (some might say irreversibly ${ }^{79}$ ) adsorbed onto cellulose (see Section 3.3.3). Thus, it provides carboxyl groups without oxidizing cellulose, thereby avoiding disruption of the hydrogen bond network and breach of the structural integrity. CMC is produced by etherification of hydroxyl groups from cellulose (primary or secondary) with monochloroacetic acid in the presence of sodium hydroxide ( $\mathrm{NaOH})$. Cellulose is first activated with sodium hydroxide in order to enhance the reactivity of the hydroxyl groups as electron donors. ${ }^{43}$ Then the activated hydroxyl groups will substitute the chloride groups from monochloroacetic acid to yield CMC (see Fig. 13). ${ }^{\mathbf{8 0 , 8 1}}$

2.2.2.4. Radical Copolymerization. Cellulose copolymers can be used for enhancing the rate of functional moieties on the cellulose surface. Therefore, they provide lots of anchoring points for biomolecule immobilization..$^{82,83}$

Copolymer grafting onto cellulose is usually performed by free radical polymerization of vinylic compounds. For initiating a graft side chain, a radical site has to be formed on the cellulose backbone. This radical can stem from the homolytic bond cleavage within the glucose unit caused by high-energy irradiation for example, from the decomposition of a functional group such as peroxide, or from a radical transfer reaction initiated by a radical formed outside the cellulose backbone during a redox reaction. The grafting is usually conducted on a solid cellulose substrate with the monomer being in solution..$^{47,67}$ 

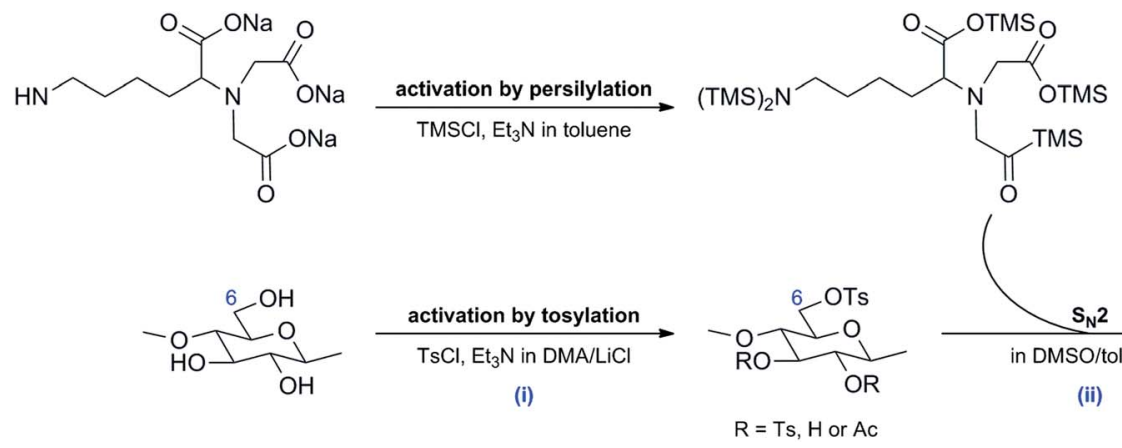

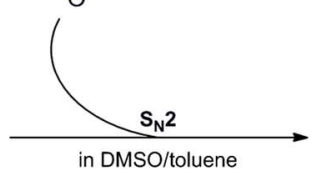

(ii)

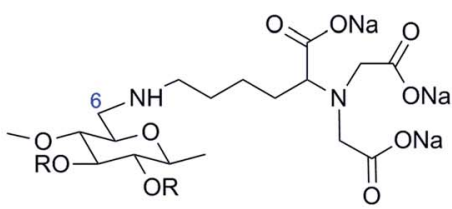

$\mathrm{R}=\mathrm{Ts}, \mathrm{H}$ or $\mathrm{Ac}$

Fig. 11 Synthesis of nitrilotriacetic acid (NTA)-modified amino-cellulose.

Table 3 Important cellulose esters and ethers commercially produced

\begin{tabular}{llll}
\hline Cellulose derivative & Worldwide production (tons per year) & Functional moiety & Application \\
\hline $\begin{array}{llll}\text { Cellulose xanthate } \\
\text { Cellulose acetate }\end{array}$ & 3200000 & $-\mathrm{C}(\mathrm{S}) \mathrm{SNa}$ & Textiles \\
Cellulose nitrate & 900000 & $-\mathrm{C}(\mathrm{O}) \mathrm{CH}_{3}$ & Coatings and membranes \\
Carboxymethyl cellulose (CMC) & 200000 & $-\mathrm{NO}_{2}$ & Membranes and explosives \\
& 300000 & $-\mathrm{CH}_{2} \mathrm{COONa}$ & $\begin{array}{l}\text { Coatings, paints, adhesives } \\
\text { and pharmaceuticals }\end{array}$ \\
Methyl cellulose & 150000 & $-\mathrm{CH}_{3}$ & Films, textiles, food and tobacco industry \\
Hydroxyethyl cellulose & 50000 & $-\mathrm{CH}_{2} \mathrm{CH}_{2} \mathrm{OH}$ & Paints, coatings, films and cosmetics \\
Ethyl cellulose & 4000 & $-\mathrm{CH}_{2} \mathrm{CH}_{3}$ & Pharmaceutical industry
\end{tabular}
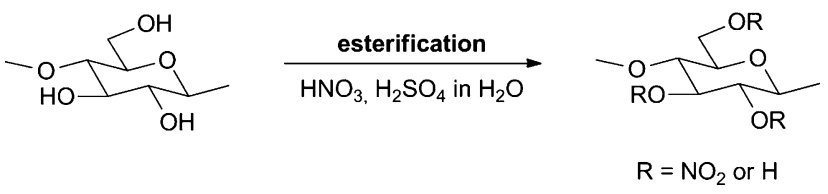

Fig. 12 Esterification of cellulose into nitrocellulose.
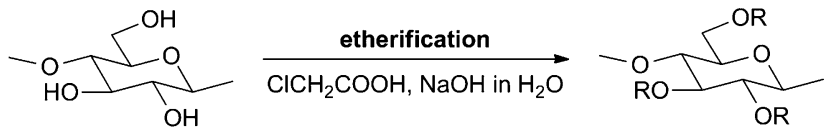

$\mathrm{R}=\mathrm{CH}_{2} \mathrm{COONa}$ or $\mathrm{H}$
Fig. 13 Etherification of cellulose into carboxymethyl cellulose.

There are many approaches to covalent attachment of polymers to surfaces. They can be classified into the following three categories: (i) the "grafting-to" method, where a pre-formed polymer is coupled with the functional groups that are located on the cellulose backbone, (ii) the "grafting-from" method, where copolymer chains grow from initiating sites on the cellulose backbone, and (iii) the "grafting-through" method, where the cellulose bares a polymerizable group, and hence acts as a macromonomer with which a smaller monomer copolymerizes. Among these three methodologies, the "grafting-from" approach is the most commonly used procedure. ${ }^{47,65}$

With regard to the polymer grafted for the biomolecule immobilization purpose previously mentioned, ${ }^{\mathbf{8 2}, \mathbf{8 3}}$ the methodology adopted is the "grafting from" technique. An initiator molecule is employed to start a radical transfer reaction and initiate the copolymerization. The initiator can be either in solution with the monomer ${ }^{83}$ or previously grafted to cellulose. ${ }^{82}$

\subsection{From papyrus to nanomaterial}

Since the Egyptian papyri, cellulose has played a significant part in human culture. For thousands of years, wood, cotton and other plant fibers were indispensable materials for clothing and building. For a long time, cellulose has been widely used as a vehicle for the acquisition, storage and dissemination of human knowledge and cultural heritage..$^{58,84}$

The use of this biopolymer as a chemical raw material began 160 years ago with the discovery of the first cellulose derivatives. Subsequently, the global production of cellulose rocketed and the cellulose processing industries such as textile industry received a great impetus by taking advantage of the chemical processes in order to improve their products quality. ${ }^{2,85}$

Nowadays, this ancient material has found new applications and has adopted new forms. For example, cellulose beads (micro- to millimeter scale particles frequently named microspheres, pellets or pearls) are used in many technologic and scientific applications such as chromatography, solid-supported synthesis, protein immobilization or retarded drug release. ${ }^{72,86}$ Moreover, since current scientific research heads towards nanomaterials, it is only logical to now encounter nanocellulose (actually fibrils, see Section 2.1.1.3) and cellulose nanocomposites. ${ }^{\mathbf{5 , 6 , 4 6 , 8 7}}$

But among all these new forms, and through all these years, paper is still by far the dominating cellulose product. ${ }^{45}$ It has 
even found its place in science with the growing area of paperbased technology. ${ }^{9}$

2.3.1. Paper. Paper was invented during the $2^{\text {nd }}$ century A.D. in China and, independently, during the $7^{\text {th }}$ century A.D. in Mesoamerica. The art craft of making paper spread from the Far East to the Western World in the Middle Ages, and for centuries, cultural resources have been accumulating in archives, libraries and museums worldwide. ${ }^{84}$

Paper is produced from a dilute aqueous suspension of cellulose fibers that is drained through a sieve, pressed and dried, to yield a sheet formed by a network of randomly interwoven fibers. The paper composition varies depending on the process applied, i.e. depending on the production period and the technology employed. In Europe during the Middle Ages, paper was made up of pure cellulose fibers from cotton, linen or hemp, usually obtained from rags (long fibers), and animal glue was added as a sizing agent. ${ }^{84}$

In contrast, contemporary paper is manufactured from wood and resultant short fibers containing hemicelluloses and lignin. The process of turning wood into paper is complex and involves many stages ${ }^{88}$ From wood to paper pulp the main steps are: logging, debarking, chipping, screening, pulping, washing, bleaching, and washing. Then, from pulp to paper sheet, there are beating, pressing, drying and rolling. ${ }^{3}$ Among these, pulping and bleaching are the most important since they aim at removing lignin, hemicelluloses and other alien substances associated with cellulose within the wood fibers (see Section 2.1.2). Yet these are chemical steps and may affect cellulose integrity. Pulping involves alkaline conditions using hydroxide $\left(\mathrm{HO}^{-}\right)$or sulfanide $\left(\mathrm{HS}^{-}\right)$whereas bleaching employs chlorine, chlorine dioxide, oxygen, ozone or hydrogen peroxide. These treatments may induce a thermal-oxidative stress in polysaccharides, resulting in the formation of various chromophores into the cellulosic pulp. ${ }^{89}$ Moreover during this long and complex process, many additives are used to improve paper properties. There are mineral particles (talc, kaolin, calcium carbonate, titanium dioxide, etc.) for the whitening purpose, sizing agents such as alkyl ketene dimer (AKD) and alkenyl succinic anhydride (ASA), dry-strength agents, etc. ${ }^{61,88,90,91}$ Thus, depending on the production process, these compounds may occur in the final cellulose product and eventually affect its physico-chemical properties.

2.3.2. Bioactive paper. It took scientists about seventeen centuries to make paper their own. They started to use it as a material platform for diagnostic devices during the $19^{\text {th }}$ century. ${ }^{10-12}$ Although paper-based bioassays such as dipsticks and lateral flow immunoassays (LFIAs) were marketed and extensively employed since the $1950 \mathrm{~s},{ }^{16-20}$ the term "bioactive paper" appeared only a few years ago, when the Sentinel Bioactive Paper Network was formed in Canada in 2005, ${ }^{34}$ and the VTT Technical Research Centre of Finland started its bioactive paper project. ${ }^{92}$

A bioactive paper can be defined as a paper-based product bearing active biomolecules. It is a key component for developing simple, inexpensive, handheld and disposable devices. ${ }^{93-95}$ Bioactive papers can be useful in many fields including clinical diagnosis, ${ }^{28,35,37,38}$ environmental monitoring ${ }^{29,39-41}$ and food quality control..$^{96-98}$ The high selectivity of biological entities (such as antibodies or enzymes) for target analytes enables bioactive papers, particularly paperbased biosensors, to be efficient sensors and powerful recognition devices. ${ }^{41}$ Moreover, simple paper-based detection devices do not require either any hardware or any specific technical skill. They are inexpensive, rapid and user-friendly and therefore highly promising for providing remote locations and resource-limited settings with point-of-care (POC) diagnostics. Therefore, paper-based biosensors have recently attracted a strong interest.

Dipsticks and lateral flow immunoassays (LFIAs) have already been widely used for point-of-care (POC) diagnostics and pathogen detection, ${ }^{21,22}$ with diabetes and pregnancy tests being the most famous. ${ }^{23,24}$ Lateral flow immunoassays (LFIAs) ensure specific and sensitive measurements of target analytes by means of the high specificity of the antibody-antigen $(\mathrm{Ab}-\mathrm{Ag})$ interaction. ${ }^{18,100,101}$ Moreover the simplicity, portability and affordability of these colorimetric detection devices make them ASSURED (Affordable, Sensitive, Specific, User-friendly, Rapid and robust, Equipment-free, and Deliverable to end-users) point-of-care diagnostic devices. ${ }^{18,19,22,38}$

Within the last ten years, the biosensing field has trended towards three-dimensional microfluidic devices and multiplexed assay platforms (Fig. 14) ${ }^{26-33}$ An effort has also been made to develop quantitative point-of-care assays. ${ }^{102}$ Multiplex assay allows detection of several analytes per sample in a single run by simultaneously carrying out multiple separate assays in discrete regions of the device. To enable more simultaneous detection while avoiding any cross-contamination, the frame material of a multiplex device needs to be patterned with microfluidic channels distributing fixed and equal volumes of a single sample to independent test zones. Regarding paperbased multiplex devices, it means either defining hydrophobic barriers and hydrophilic channels on a piece of cellulose paper or shaping the paper by cutting..$^{95}$ Several methods for patterning paper sheets have been developed ${ }^{30,95}$ Among the many processes are photolithography, using SU-8 or SC photoresist, ${ }^{25,35,99,103}$ "wax printing" or "wax dipping", ${ }^{104-106}$ inkjet printing ${ }^{107}$ and laser cutting. ${ }^{108,109}$

Nitrocellulose is the classical material for biomolecule immobilization in LFIAs. ${ }^{18-20,78}$ However, this cellulose derivative is relatively expensive, crumbly, flammable ${ }^{\mathbf{1 1 0 , 1 1 1}}$ and cannot withstand most of procedures implemented in the development of new multiplex sensors, ${ }^{\mathbf{8}, 30,95}$ mostly because many of them include a step in which the paper temperature rises above $100^{\circ} \mathrm{C} .{ }^{104,99}$ This is why the new multiplexed bioassay platforms tend to replace nitrocellulose by pure cellulose which is much more convenient to handle and more safely disposable. ${ }^{8}$ Moreover, its bioavailability and biodegradability make cellulose a very attractive material regarding the current economic and ecological climate.

Finally, efficient paper-based bioassays require membranes where biosensing entities such as antibodies are numerous and strongly immobilized. ${ }^{93}$ Besides, the immobilization strategy greatly influences biosensor properties. ${ }^{112,113}$ The immobilization of biomolecules onto cellulose paper is therefore a key step 
(a)

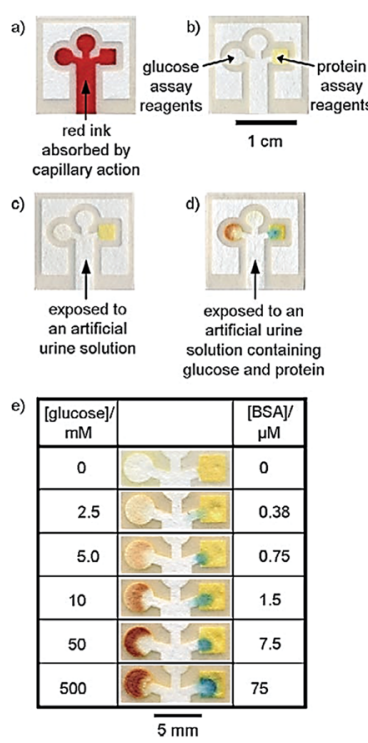

(b)



(c)

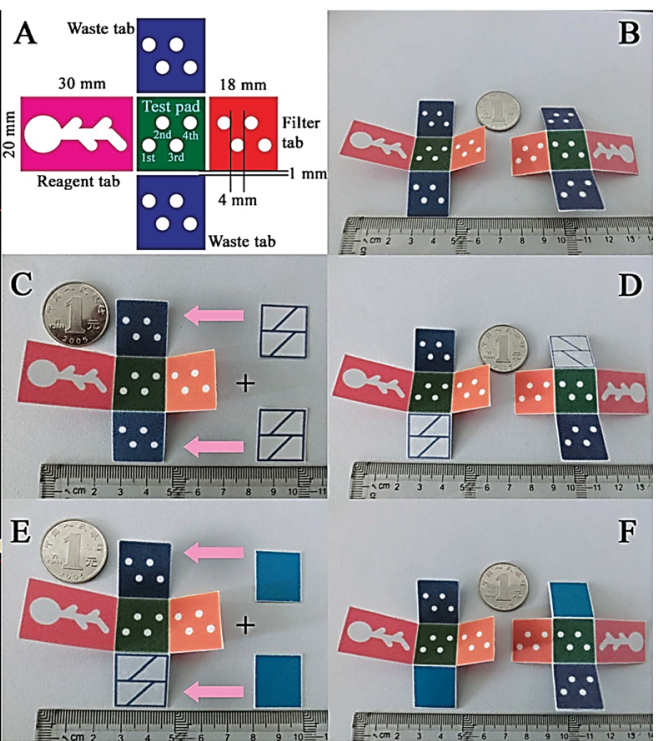

Fig. 14 Few multiplexed assay platforms ( $a, b$ and c) and three-dimensional microfluidic device (c) (with (a) reprinted with permission from ref. 99, Copyright (c) 2007 WILEY-VCH Verlag GmbH \& Co. KGaA, Weinheim; (b) reprinted with permission from ref. 26, Copyright 2009 American Chemical Society; (c) reproduced from ref. 33).

in the development of such paper-based sensing devices and bioactive papers in general. Many procedures exist and the following part of this article reviews and categorizes the current techniques for the immobilization of biomolecules onto pure cellulose. A lot of these approaches are not specific to cellulose and can also be conducted on other substrates such as gold or glass. Thus, the methodologies exposed will sometimes be very general. But all the processes presented and all the reactions mentioned thereafter were performed on the pure cellulose substrate.

\section{Biomolecule-bearing cellulose: a bioactive material}

Immobilization of biomolecules on a solid support has many advantages. ${ }^{114}$ It simplifies purification procedures and downstream processing, enables saving and reusing these quite expensive macromolecules and improves their stability. ${ }^{114-116}$ Thus, it is often a prerequirement for their utilization in commercial scale processes. ${ }^{116,86}$ A few established large-scale applications for immobilized biocatalysts are shown in Table 4 .

Immobilization of a molecule can be defined as its attachment to a surface leading to reduction or loss of its mobility. ${ }^{112}$ Random orientation and structural deformation of biomolecules during immobilization may reduce their biological activity. ${ }^{117}$ Thus, immobilization pathway significantly influences biosensor or biochip properties. ${ }^{112,113}$ The main objective should therefore be to control not only the location and density of biomolecules, but also their tertiary structure and their orientation, in order to fully retain or even enhance their biological activity. ${ }^{94,112}$ However, there is no universal immobilization method. For a given biochip, the choice of the most appropriate immobilization strategy should take into consideration the physicochemical and chemical properties of both surfaces and biomolecules, ${ }^{112}$ the type of transduction used, the nature of the sample intended to be tested and the possibility of multiple use of the sensor. ${ }^{93,113}$ Reproducibility, cost and complexity of the immobilization process also need to be considered, especially if industrialization is planned. ${ }^{113}$

With regard to cellulose-based biosensors, immobilization methods which are compatible with automated coating and printing techniques facilitate large-scale and low-cost applications. ${ }^{93}$ Cellulose is a rather inexpensive biopolymer, but biomolecules are expensive and must be used efficiently. They should be retained on the extreme surface of the paper substrate in order to be more easily and more quickly accessible to the target, and most importantly in order to concentrate the sensing signal in a visible area (within $10 \mu \mathrm{m}$ deep)..$^{93,94,118}$

There are many approaches to attachment of biomolecules to cellulose. They can be classified into the following three categories: (i) physical methods, where the biomolecule is confined to the support surface because of physical forces (e.g. van der Waals, electrostatic or hydrophobic interactions and hydrogen bonding), (ii) biological or biochemical methods, where the biomolecule is bound to the substrate because of biochemical affinity between two components $\left(\right.$ e.g. $\mathrm{Ni}^{2+} / \mathrm{His}$-tag, streptavidin/biotin, protein $\mathrm{G} /$ human $\mathrm{IgG}$ ), and (iii) chemical methods, where covalent bonds fix the biomolecule to the support surface.

\subsection{Physical methods}

Physical methods have the advantage of keeping denaturation of the immobilized biomolecules to a minimum. ${ }^{119,120}$ There are conducted in very few steps, with no chemical modifications of 
Table 4 Large scale industrial processes using immobilized biomolecules

\begin{tabular}{lll}
\hline Enzyme & Process & Production (tons per year) \\
\hline Glucose isomerase & High fructose corn syrup from corn syrup & $10^{7}$ \\
Nitrile hydratase & Acrylamide from acrylonitrile & $10^{5}$ \\
Lactase & Lactose hydrolysis, GOS synthesis & $10^{5}$ \\
Lipase & Transesterification of food oils & $10^{5}$ \\
& Biodiesel from triglycerides & $10^{4}$ \\
Penicillin G acylase & Chiral resolution of alcohols and amines & $10^{3}$ \\
Aspartase & Antibiotic modification & $10^{4}$ \\
Thermolysin & L-Aspartic acid from fumaric acid & $10^{4}$ \\
\end{tabular}

either the surface or the biomolecule. They are therefore simple, fast and economical.

However, the bond between the biomolecule and the cellulose surface is weak and temporary. Biomolecules tend to leak from the support resulting in a gradual loss of biosensor activity. Overloading the support with biomolecules may compensate for leakage, but would increase the cost of the device. In addition, the physical interactions binding biomolecules to the substrate are nonspecific ${ }^{\mathbf{1 2 0 , 1 2 1}}$ and lead to random orientation. ${ }^{112,113}$

Fig. 15 presents the three main physical approaches to immobilization of biomolecules onto cellulose.

3.1.1. Direct adsorption. Adsorption is the simplest immobilization method. The biomolecule and the support are directly bound by reversible noncovalent interactions such as van der Waals, electrostatic or hydrophobic interactions or hydrogen bonding. ${ }^{113}$ The strength of the bond therefore varies depending on the interactions at work. Hydrophobic interactions are strong and may cause structural changes in the adsorbed biomolecules and eventually result in the loss of activity. ${ }^{\mathbf{9 4 , 1 2 0}}$ Considering that cellulose is hydrophilic and slightly anionic (see structure in Fig. 1), adsorption results from van der Waals forces, hydrogen bonding and ionic interactions depending on the experimental conditions. ${ }^{47,93}$ Thus, proteins readily adsorb onto cellulose via their cationic patches and tyrosine groups, whereas DNA is repulsed because of its anionic phosphate groups. ${ }^{9394}$ But, whatever conditions picked, interactions at work are not strong enough to ensure permanent immobilization and prevent biomolecules from leaking from cellulose. Moreover, the density of adsorbed biomolecules is often low. ${ }^{93}$

The procedure consists of placing the support in contact with the biomolecules, under suitable conditions of $\mathrm{pH}$ and ionic strength for a fixed period of incubation. The support is then thoroughly rinsed to eliminate the non-immobilized species. ${ }^{121}$

This method is hardly used to develop cellulose-based biosensors ${ }^{32,37,99,122-126}$ because the amount of molecules adsorbed onto cellulose varies a lot depending on the nature of the biomolecule. ${ }^{127}$ Many of them will actually desorb from the fibers (about $40 \%$ for antibody molecules). ${ }^{\mathbf{1 1 9 , 1 2 8}}$ It is therefore difficult to perform sensitive and reproducible analysis this way. Hence, this method is mostly used when biomolecules need to be released, as in blood typing: ${ }^{128-131}$

3.1.2. Adsorption of carrier particles: bioactive inks. This method can be considered as a variant to direct adsorption. A component does adsorb onto cellulose because of physical interactions, but it is not the biomolecule itself. It is a carrier particle onto (or into) which the biomolecule is immobilized. Suspensions of such colloidal particles loaded with biomolecules are called bioactive inks. They can be printed, coated or even added during the paper-making process.

This technique has an advantage over classical physisorption: playing with particle size makes it possible to concentrate biomolecules onto exterior surfaces of porous papers. ${ }^{93}$ Usually used papers have particle retention ranging from 2.5 to $40 \mu \mathrm{m}^{128,131,132}$ Thus, antibodies (about $24 \mathrm{~nm}$ lateral) ${ }^{133}$ or enzymes easily go through the fiber lattice. In
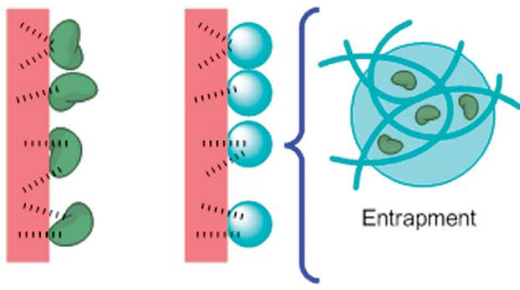

OR

Direct

Adsorption
Carrier Particles

Adsorption

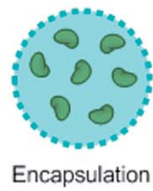

OR
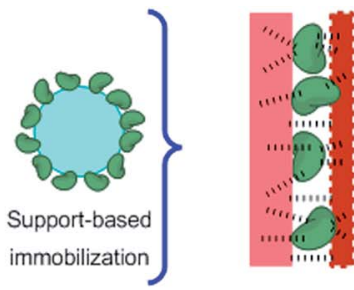

Confinement

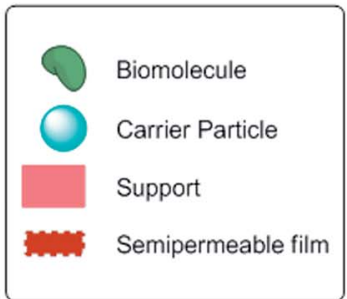

Semipermeable film

Fig. 15 Physical approaches to immobilization. 
contrast, $\quad 0.5$ micrometer-scale particles ${ }^{\mathbf{1 3 4 , 1 3 5}}$ have size approaching particle retention values and are thereby more easily retained on the surface. Therefore, carrier particles enable immobilizing more biomolecules closer to the surface. ${ }^{\mathbf{1 3 4}}$ In addition, biomolecules immobilized within carrier particles are protected from the external environment and its variations. ${ }^{136}$ However, mass transfer limitations and pore-clogging may keep the biomolecules away from their target and eventually result in the loss of efficiency. ${ }^{\mathbf{9 3 , 1 2 1 , 1 3 6}}$ On the other hand, immobilization of biomolecules over the carrier particles may also reduce the activity by diluting the bio-signal as carriers can account for up to $99 \%$ of the immobilized mass or volume. ${ }^{136}$

Immobilization of biomolecules onto (or into) carrier particles can be performed by any other technique described in this paper: physisorption, ${ }^{\mathbf{1 3 4}}$ covalent coupling ${ }^{\mathbf{9 4 , 1 3 7}}$ or bioaffinity attachment. ${ }^{\mathbf{1 3 5}}$ These particles are made of either inorganic compounds such as silica ${ }^{\mathbf{1 3 7}}$ or polymers. ${ }^{\mathbf{9 4 , 1 3 4 , 1 3 5}}$ Immobilization of biomolecules within the carrier particles is achieved by entrapment or encapsulation (Fig. 15). Lines are blurred between these two notions. In either case, the biomolecule is still free in solution, but restricted in movement. In the encapsulation process, capsule is responsible for the confinement. In the other process, a lattice structure is accountable for the molecule entrapment. ${ }^{\mathbf{1 2 1 , 1 3 6}}$ Particle is built around the biomolecule which is therefore trapped into the carrier material. Pore size of the capsule (or porosity of the lattice) is defined to ensure that large molecules, such as biomolecules, cannot leak from the particle while small substrates and products can freely go through it and access the biomolecule. ${ }^{\mathbf{1 1 9 , 1 2 1 , 1 3 6}}$

3.1.3. Confinement. This technique is halfway between direct adsorption and encapsulation. After adsorption onto the support, the biomolecule deposit is covered with a semipermeable film which will adsorb as well as hold biomolecules in place. Like in the encapsulation process, pore size of the film is defined to allow small analytes to go through while restricting biomolecules motion. Biomolecules are therefore confined between the film and the cellulose surface. The chemical properties of the film can be tuned in order to increase its selectivity regarding crossing species. ${ }^{97,138}$ In addition, films made of polyelectrolyte increase cohesion between layers through electrostatic forces. ${ }^{39,139}$ These films are either thin layers made of polymers ${ }^{39,97,139}$ or actual membranes. ${ }^{138}$

The most famous confinement membrane is the dialysis membrane. ${ }^{119}$ Dialysis membranes are made of regenerated cellulose. ${ }^{\mathbf{1 4 0 , 1 4 1}}$ These films only contain cellulose II which is the most stable of cellulose crystal structures., ${ }^{2,47,142}$ This structure can be formed from native cellulose (cellulose I) by dissolution, chemical treatment and precipitation (regeneration of the cellulose solid form). ${ }^{2}$ There are many processes of producing regenerated cellulose.

As for semipermeable thin films, there can be either just one film or several stacked-up films. The latter arrangement is called the layer by layer technique (LbL). Biomolecules and polyelectrolytes with opposite charges are alternately deposited onto the cellulose. They adsorb and stick together because of electrostatic interactions between alternate layers and eventually result in stabilization of the whole system..$^{39,113,139}$

\subsection{Biological methods: bioaffinity attachment}

Bioaffinity approaches have the advantage of ensuring controlled orientation of the immobilized biomolecules. Wisely chosen orientation guarantees fully retained biological activity. Incidentally, immobilized biomolecules may appear more active than biomolecules in solution, ${ }^{\mathbf{1 1 5}}$ most likely because of the improvement of their stability and the increase of volume specific biomolecule loading. ${ }^{116}$ Besides, although it is noncovalent, bioaffinity attachment is specific and strong, and thus produces robust biosensors. In addition, bioaffinity attachment is reversible and therefore gives the opportunity to develop regenerable and versatile biosensors or even biomolecule purification systems. ${ }^{112,120}$

However, this technique is complex because it usually requires modifications of both biomolecules and substrates. One of the binding partners has to be immobilized onto the support and the other has to be conjugated or expressed in the biomolecule, preferably far away from the active site in order to keep it unspoiled and within reach of its target. Affinity tags are expressed in biomolecules by genetic engineering methods such as site-directed mutagenesis, protein fusion technology and post-transcriptional modification. These methods enable placing tags at well-defined positions on proteins. Unfortunately these methods are very complex, expensive and timeconsuming. ${ }^{\mathbf{1 1 2 , 1 1 3 , 1 2 0}}$

There are two biological approaches to immobilization onto cellulose (Fig. 16). The usual bioaffinity attachment implements modifications of both biomolecules and substrates. Interacting components are protein/ligand, protein/antibody or metal ion/ chelator (e.g. streptavidin/biotin, protein G/human IgG and $\mathrm{Ni}^{2+} /$ His-tag, respectively). The other bioaffinity attachment method is specific to cellulose which can be one of the binding partners. The cellulose substrate is therefore bound to a special protein domain introduced into the biomolecule by genetic engineering: the cellulose-binding domain (CBD).

3.2.1. Cellulose-binding domain (CBD)/cellulose. This is the only method for bioaffinity attachment which does not require modifications of the substrate since it is one of the binding partners. Binding partners are thus cellulose substrates and cellulose binding domains (CBDs) expressed in biomolecules. CBD is a protein domain which can be found in cellulosedegrading enzymes. Its tasks are to make the substrate accessible to the enzyme and to concentrate catalyzing domains on insoluble cellulose substrates. This is why CBD spontaneously

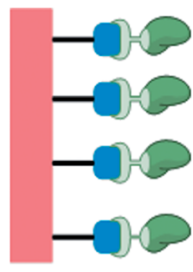

Bioaffinity couple bonding

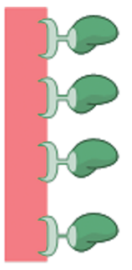

Cellulose-binding

domain (CBD)
Fig. 16 Biological approaches to immobilization. 
adheres to cellulose and can be used as a binding partner. This capacity is partly due to interactions involving several aromatic amino acids from the hydrophobic surface of CBD, as well as hydrogen bonding and van der Waals interactions. ${ }^{\mathbf{1 4 3 , 1 4 4}}$ CBDs are classified into 14 different families based on amino acid sequences, structures and binding specificities. ${ }^{143}$ Their size may vary from 3 to $20 \mathrm{kDa}$ and their location within proteins may be $\mathrm{N}$ terminal, C-terminal or internal. Some CBDs bind irreversibly to cellulose, whereas others bind reversibly. The latter enable attached proteins to be released from cellulose with denaturing or gentle elution solutions, or even by temperature switches, depending on the CBD's type. ${ }^{\mathbf{1 4 4 , 1 4 5}}$

Biomolecules that have been fused with CBDs can thus spontaneously bind to cellulose. ${ }^{93,94}$ Fusion proteins can therefore be purified by reversible immobilization onto the cellulose column. ${ }^{146}$ Immobilized fusion enzymes can be used to produce biocatalysts displaying enhanced performance. ${ }^{115,147,148}$ Antibodies directly fused with CBDs, ${ }^{\mathbf{1 3 2}, \mathbf{1 4 9}}$ or interacting with CBDfused protein $\mathrm{A},{ }^{\mathbf{1 5 0}}$ can be immobilized onto cellulose and used to achieve immunoassays.

Finally, fusion with proteins such as protein $A,{ }^{150}$ protein $\mathrm{G}$, protein $\mathrm{L}^{151}$ or streptavidin ${ }^{152}$ turns CBDs into bifunctional affinity linkers ${ }^{94}$ (see Section 3.2.3).

3.2.2. Protein/ligand. One of the binding partners is first covalently bound to cellulose and then exposed to the other binding partner. Both configurations are equally employed: either a ligand which is bound to cellulose would fix a protein ${ }^{153,154}$ or a protein which is bound to cellulose would fix a ligand-fused protein..$^{73,152,155,156}$

There are many protein/ligand couples usable for bioaffinity attachment, among which are avidin/biotin, ${ }^{73,152,155-158}$ calmodulin/phenothiazine, ${ }^{153}$ and plasminogen activators/para-aminobenzamidine. ${ }^{\mathbf{1 5 4}}$ The avidin protein family is composed of multimeric proteins which are able to bind several biotins at once. They can be used as a bifunctional affinity linker, and therefore make possible to attach biotinylated proteins to biotinylated cellulose. ${ }^{157-159}$ The (strept)avidin-biotin bond is one of the strongest noncovalent bonds ever known $\left(K_{\mathrm{d}} \approx 10^{-15}\right.$ M). ${ }^{113}$ This bond forms quickly and insensitively to $\mathrm{pH}$, temperature or solvent. ${ }^{112}$ Avidin/biotin is the most widely used couple. Therefore, many biotinylated proteins and biotinylation kits are commercially available (Biotin Conjugated Proteins and Enzymes \& Biotin Labeling Reagents for Proteins, Thermo Fisher Scientific Inc., Rockford, IL, USA).

3.2.3. Protein A, G or L/antibody. Proteins A, G and L are sometimes called "antibody-binding domains". ${ }^{151}$ They specifically interact with the Fc constant region of immunoglobulin $\mathrm{G}$ (IgG) molecules which are the usual antibodies for immunoanalysis (Fig. 17). ${ }^{\mathbf{1 6 0}}$ Although noncovalent, the resulting bond is quite strong. For instance, the dissociation constant $\left(K_{\mathrm{d}}\right)$ of the protein G-human IgG bond is about $10^{-8} \mathrm{M}$. While protein A is only able to bind to certain classes of mammalian immunoglobulins, protein $\mathrm{G}$ displays broader binding activity. ${ }^{\mathbf{1 1 2 , 1 6 1}}$

These proteins can be immobilized onto cellulose by any other technique described in this paper: physisorption, ${ }^{\mathbf{1 5 0}}$ covalent coupling ${ }^{\mathbf{1 5 0}}$ or bioaffinity attachment. ${ }^{151}$ Then, when they are fixed to cellulose, these proteins ensure specific and

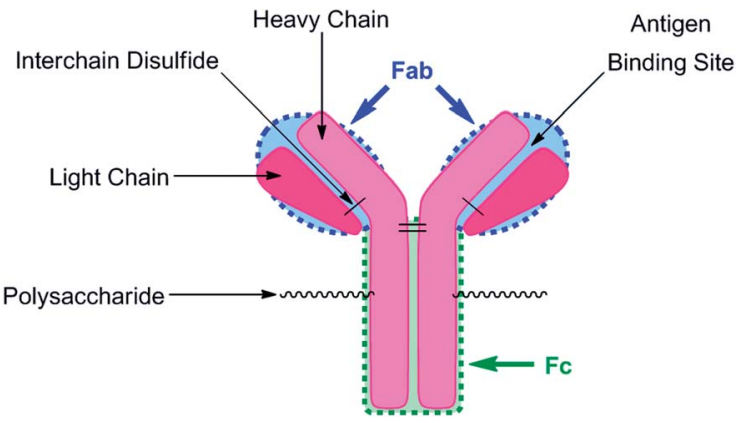

Fig. 17 Detailed structure of an IgG antibody molecule.

ideally-oriented immobilization of antibodies. Indeed, since these proteins fix antibodies by their Fc part, the Fab variable regions point in the opposite direction to the support. Therefore, as they are located on these Fab regions (Fig. 17), ${ }^{\mathbf{1 6 0}}$ the antigen-binding sites remain well accessible for binding with their antigens. ${ }^{\mathbf{1 1 2}}$ The specificity of this coupling is used for the purification purpose, ${ }^{\mathbf{1 5 1 , 1 6 2}}$ while the orientation is useful for developing sensitive immunosensors. ${ }^{150}$

3.2.4. Metal ion/chelator. The affinity link between a metal cation and a chelator is a specific and strong noncovalent interaction which forms rapidly. Polyhistidine tag (also called His-tag) is the most popular chelator due to the advantages of small size and charge (in relation to the conjugated protein), low immunogenicity, compatibility with organic solvents, and effective purification. Its size may vary from 2 to 10 histidine residues, but hexahistidine (His) ${ }_{6}(0.84 \mathrm{kDa})$ is the most widespread form. Its location within protein may be $\mathrm{N}$-terminal or Cterminal. Electron donor groups on the histidine imidazole ring readily form coordination bonds with transition metal ions such as $\mathrm{Co}^{2+}, \mathrm{Ni}^{2+}, \mathrm{Cu}^{2+}$ or $\mathrm{Zn}^{2+} \cdot{ }^{112,144}$ The strength of the bond varies depending on the cation and stands in the following order: $\mathrm{Cu}>\mathrm{Ni}>\mathrm{Co}$. Slight modifications may occur depending on the other chelators in the complex. ${ }^{\mathbf{1 6 3}}$ Nevertheless, those divalent cations not only bind to histagged proteins, but also to endogenous proteins that contain histidine clusters. The specificity of the metal-His-tagged protein interaction over metalendogenous protein interactions stands in the following order: $\mathrm{Co}>\mathrm{Ni}>\mathrm{Cu}$. Thus, since cobalt exhibits the most specific interaction with histidine tags, it is the preferred cation for purifying His-tagged proteins. On the other hand, copper provides the strongest but least specific interaction. It would therefore be useful for binding previously purified proteins. Nickel is the most widely available metal ion for purifying Histagged proteins. The reason is that nickel is a good compromise between strength and specificity of the chelating interaction. Incidentally, the specificity can be adjusted depending on working conditions. ${ }^{\text {144,164-166 }}$

His-tagged proteins can be easily immobilized onto a chelate-modified surface via a metal-chelated complex, usually a nickel complex. A matrix ligand such as nitrilotriacetic acid (NTA) or imidodiacetic acid (IDA) is first covalently bound to the surface and then loaded with the metal cation. The chelating interaction between His-tagged biomolecules and the $\mathrm{Ni}^{2+}$-NTA 
complex involves the octahedral coordination of the nickel ion (Fig. 18a): two valences are occupied by two imidazole groups from the His-tag and the others by four ligands from the NTA molecule. ${ }^{112,113}$ This immobilization is strong $\left(K_{\mathrm{d}} \approx 10^{-13} \mathrm{M}\right)^{165}$ but reversible and the surface can be regenerated under mild conditions using competitive agents or acidic $\mathrm{pH}$. Ligands such as imidazole or any other Lewis base will replace histidine in the complex, while chelating ligands such as ethylenediaminetetraacetic acid (EDTA) will remove the metal cation, both resulting in freeing His-tagged proteins. ${ }^{\mathbf{1 1 3 , 1 6 6}}$ This technique is the most widely used procedure for purifying proteins. Another complex that is sometimes employed to purify His-tagged proteins is cobalt and carboxylmethylaspartate (CMA) (Fig. 18b). Both $\mathrm{Ni}^{2+}-\mathrm{NTA}$ and $\mathrm{Co}^{2+}-$ CMA matrixes have a binding capacity ranging from 5 to $10 \mathrm{mg}$ protein per $\mathrm{mL}$ of the matrix resin. ${ }^{\mathbf{1 4 4 , 1 6 5}}$

Several complexes have been used onto cellulose. There is the usual His-tag- $-\mathrm{Ni}^{2+}-\mathrm{NTA},{ }^{76}$ but also His-tag-Co ${ }^{2+}-\mathrm{IDA},{ }^{72}$ or even the titanium-biotin couple. ${ }^{159}$ They were used either for the purification purpose,$^{72}$ or for developing diagnostic systems. ${ }^{76}$

\subsection{Chemical methods}

Chemical approaches ensure strong, stable and permanent attachment of biomolecules to cellulose. These methods provide robust biosensors with reproducible results. Moreover, thermal stability of the immobilized biomolecules may increase. ${ }^{121,167}$

On the other hand, these techniques usually require activation or modifications of both substrates and biomolecules. This makes the process more complex and expensive. In addition, these chemical modifications may induce structural changes in biomolecules and a potential partial loss of activity, thereby resulting in the loss of biosensor sensitivity. Furthermore, chemical attachment of biomolecules is not reversible. Immobilized biomolecules cannot be retrieved and used elsewhere later on. But this does not mean that it is not possible to produce regenerable sensors this way. Provided that the sensing biomolecule can be harmlessly free from its analyte (e.g. antibody from antigen), the sensor can be used several times.

There are three chemical approaches to immobilization onto cellulose (Fig. 19). These are the most common methods for coupling biomolecules to cellulose. Hence, many activating and crosslinking reagents are commercially available. ${ }^{\mathbf{1 6 8}}$

3.3.1. Crosslinking. This method has the advantage of immobilizing a large amount of biomolecules onto the support, but is quite expensive. $\mathrm{Bi}$ - or multifunctional reagents make biomolecules covalently bind not only to the substrate but also to each other, resulting in a large three-dimensional structure. Since biomolecules are randomly bound to each other, the amount of immobilized biomolecules varies a lot and the attachment process is poorly reproducible. Moreover, distribution and orientation of the immobilized biomolecules are random too, and so are the number and location of anchoring points within biomolecules. All of this may stiffen the biomolecule structure, or even block or distort the active site, what may eventually result in a huge loss of activity. ${ }^{\mathbf{1 1 3 , 1 2 1 , 1 6 9}}$

Yet, crosslinking is pretty attractive due to its simplicity. This is a one-step procedure which consists of placing the support in contact with the biomolecules together with the crosslinking agent. Glutaraldehyde is a dialdehyde and certainly the most famous bifunctional crosslinker. ${ }^{28,33,83,105,170,171}$ It binds primary amines together by forming imine groups on each of its extremities. Imines can be reduced into secondary amines in order to get more stable bonds. Biomolecules, especially proteins, hold lots of primary amines, but cellulose does not. It is therefore necessary to first functionalize cellulose, what is usually done by polymer coating. ${ }^{28,33,105,170,171}$ Like cellulose, chitosan is a natural biopolymer made up of glucose units which contains secondary amine moieties. It readily and strongly adsorbs to cellulose because of this structural similarity and its slightly cationic charge in aqueous medium (cellulose is slightly anionic in water). ${ }^{\mathbf{1 0 5 , 1 7 2}}$ It is therefore one of the most coated polymers.

3.3.2. Direct covalent bonding. Covalent bonding is the strongest immobilization method. The biomolecule and the support are directly linked by nonreversible covalent bonds between functional groups from both support and biomolecule surfaces. ${ }^{\mathbf{1 2 1}}$ Functional groups potentially available in proteins for covalent bonding are amine, thiol, carboxyl and hydroxyl groups. ${ }^{112}$ The corresponding amino acids, together with the functionalities required on surfaces for attachment are detailed in Table 5. Most of the time, covalent immobilization involves lysine residues (primary amine group) because they are typically present on the surface of the macromolecule, and are usually (a) His-tag--Ni ${ }^{2+}-$-NTA

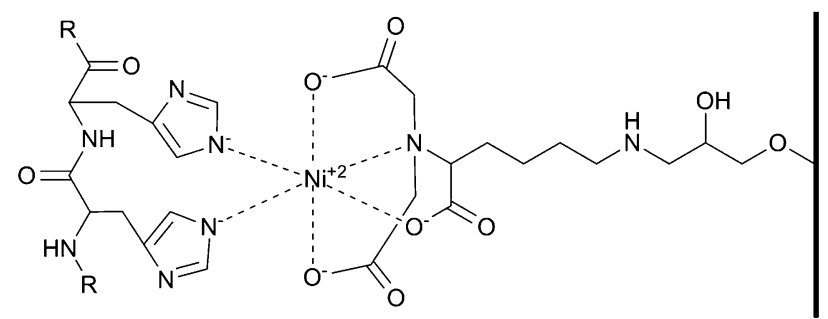

(b) His-tag---Co ${ }^{2+}-$-CMA

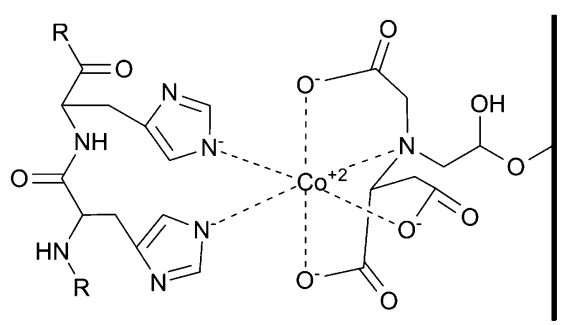

Fig. 18 Models of the interactions between the polyhistidine affinity tag and two immobilized metal affinity chromatography matrices: (a) the nickel-nitrilotriacetic acid matrix $\left(\mathrm{Ni}^{2+}-\mathrm{NTA}\right)$. (b) The cobalt-carboxylmethylaspartate matrix $\left(\mathrm{Co}^{2+}-\mathrm{CMA}\right)$. 


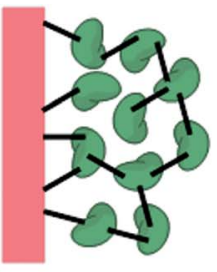

Crosslinking

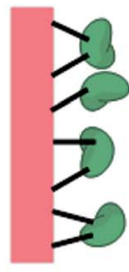

Direct covalent bonding


Bonding to

a primer

Fig. 19 Chemical approaches to immobilization.

numerous. Yet, if several groups of one biomolecule take part in its attachment (multipoint attachment), its flexibility may be reduced along with its activity. ${ }^{86,112,173}$ Likewise, if the active site of the biomolecule contributes to the bonding, its activity may also be affected. According to the molecular structure of cellulose (Fig. 1), hydroxyl groups in glucose units are responsible for its chemical activity. Among the three hydroxyl groups in each glucose residue, the one at 6-position (primary one) is described as the most reactive site, far more than hydroxyl groups at 2-and 3-positions (secondary ones). ${ }^{47}$ However, this group cannot directly react with amines, which makes cellulose activation or functionalization necessary in order to covalently bind to proteins.

Covalent bonding usually implements multistep reactions because substrates and/or biomolecules need to be activated before they can react with each other. There are many procedures, but activation methods as well as the nature of the linking bonds are still pretty much the same. ${ }^{86,121}$ Generally, biomolecules are linked to cellulose by forming bonds such as amide ${ }^{8,73,74,173}$ imine ${ }^{40,83,174}$ secondary amine ${ }^{8,68,71,150,173,175-178}$ and isourea ${ }^{179}$ or carbamate ${ }^{180}$ (Fig. 20).

Amide bonds are formed by reaction of primary amines from lysine residues with activated esters previously introduced in cellulose, usually $N$-hydroxysuccinimide esters. To form these esters, primary alcohol groups from cellulose are first oxidized into the corresponding carboxylic acids by TEMPO-mediated oxidation $^{73,74}$ (see Section 2.2.2.1). Then, those carboxylic acids react with a mixture of 1-ethyl-3-(3-dimethylaminopropyl)carbodiimide hydrochloride (EDC) and $N$-hydroxysuccinimide (NHS) to form the activated succinimide esters ${ }^{73,74,173}$ (Fig. 21).

Imine bonds are produced by condensation of primary amines from biomolecules with carbonyl groups from cellulose. These carbonyl groups may originate from the oxidation of secondary alcohol groups in glucose units, usually by periodate oxidation $^{40,71,72}$ (see Section 2.2.2.1) (Fig. 22a). They may also stem from the cellulose functionalization with glutaraldehyde $(\mathrm{GA})^{83,150,174}$ (Fig. 22b).

Those imine bonds are sometimes reduced into secondary amines in order to get more stable bonds. Sodium borohydride $\left(\mathrm{NaBH}_{4}\right)^{72,150}$ and sodium cyanoborohydride $\left(\mathrm{NaBH}_{3} \mathrm{CN}\right)^{71,72}$ are the usual reducing agents (Fig. 23a). Finally, secondary amines may also result from nitrene insertion ${ }^{8,68,175}$ (Fig. 23b) or epoxide ring-opening ${ }^{72,173}$ (Fig. 23c).

Many activating and linking reagents are commercially available (Crosslinking Reagents, Thermo Fisher Scientific Inc., Rockford, IL, USA). ${ }^{168}$ Whatever bond is chosen, coupling efficiency depends on parameters such as $\mathrm{pH}$, concentration, ionic strength and incubation time. Most importantly, the bonding conditions and parameters need to be optimized for each type of biomolecule. ${ }^{112}$

Table 5 Commonly available functional groups in proteins and surface functionalities required for attachment

\begin{tabular}{lll}
\hline Side groups & Amino acids & Surface functionalities \\
\hline$-\mathrm{NH}_{2}$ & Lysine & Carboxylic acid, active ester (NHS), epoxy, aldehyde \\
$-\mathrm{SH}$ & Cysteine & Maleimide, pyridyl disulfide, vinyl sulfone \\
$-\mathrm{COOH}$ & Aspartic acid, glutamic acid & Amine \\
$-\mathrm{OH}$ & Serine, threonine & Epoxy
\end{tabular}
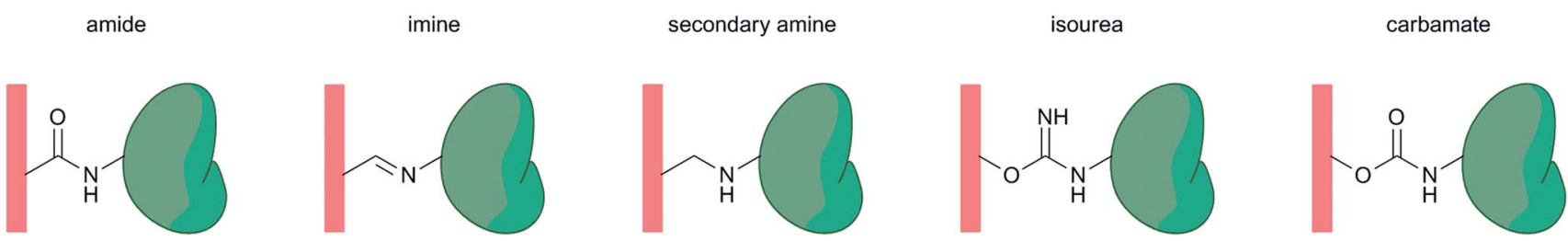

Fig. 20 Nature of the linking bonds between cellulose substrates and biomolecules. 



carboxyl cellulose

succinimide ester

Fig. 21 Amide bond formation.

(a)
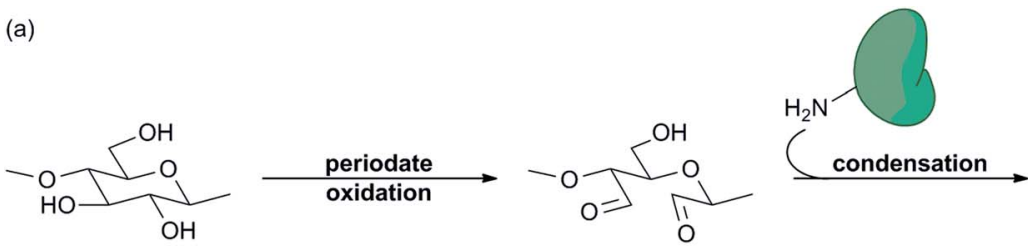

carbonyl cellulose condensation



(b)
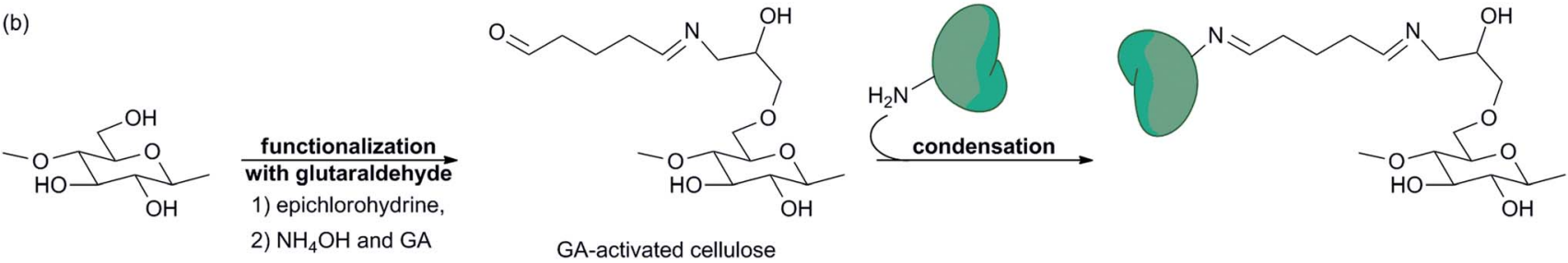

Fig. 22 Imine bond formation (a) through periodate oxidation of cellulose and (b) through functionalization with glutaraldehyde.

3.3.3. Bonding to a polymeric primer. This method can be considered as a variant to direct covalent bonding and may be described as semicovalent. The biomolecule does bind covalently to a substrate, but it is not cellulose itself. It is a polymeric primer previously coated and strongly adsorbed onto cellulose. This polymer provides the functional groups required for covalent bonding and it provides them in large quantities. This technique has the advantages of making the activation of the cellulose substrate simpler and reducing the number of reaction steps. However, since the polymer can desorb from cellulose, this method is less robust than actual covalent bonding.

Many different polymers can be used, but these usually are polysaccharides such as chitosan and carboxymethyl cellulose (CMC) which provide amine and carboxyl groups, respectively (Fig. 24). ${ }^{28,33,73,79,105,170,171,181}$ With regard to CMC, some may consider its adsorption onto cellulose as nonreversible. ${ }^{79}$ As for chitosan, chemical interactions between the latter and cellulose have been highlighted. According to this study, amine groups from chitosan react with carbonyl groups from cellulose to produce imines. ${ }^{182}$ Carbonyl groups can be found at the reducing end group of pristine cellulose or anywhere in the structure of aged cellulose. ${ }^{61,183}$

Finally, another configuration can be employed sometimes. The polymeric primer is first covalently bound to cellulose by radical copolymerization, while the biomolecule is further adsorbed to it. ${ }^{\mathbf{1 6 7 , 1 8 4}}$ Thus, the biomolecule is less likely to get distorted, but the biological material is more likely to leak.

\section{Summary and outlook}

It has been a long road from papyrus to bioactive paper. Since its invention over five thousand years ago in Egypt, papyrus had long been the dominant writing material. It was then supplanted in Europe by parchment and eventually paper during the Renaissance. Paper's main component, cellulose, was identified during the $19^{\text {th }}$ century by a French chemist and was further used as a chemical raw material, hence giving impetus to textile industry. Paper-based bioassays appeared during the 1950 s and were then extensively applied to point-of-care diagnostics. Finally, the term "bioactive paper" came into use in the 2000s.

Recently, paper-based bioassays have trended towards threedimensional devices and multiplexed assay platforms. Most of the procedures implemented in the production of such sensors are incompatible with the conventional lateral flow immunoassay (LFIA) carrier material, nitrocellulose. In newly developed multiplex biosensors, nitrocellulose thus tends to be replaced by pure cellulose which, besides being more convenient to handle and more safely disposable, is a very attractive material regarding the current ecological climate and growing will for sustainable technologic development. 
(a)

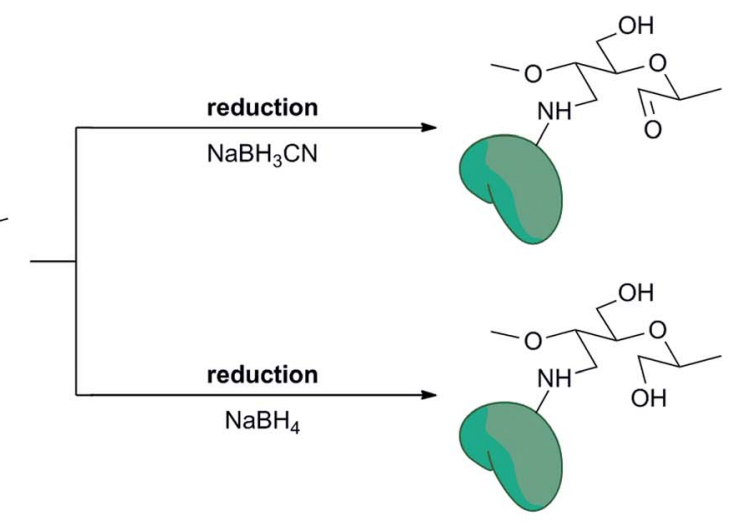

(b)


(c)

L-Ascorbic acid in $\mathrm{H}_{2} \mathrm{O}$
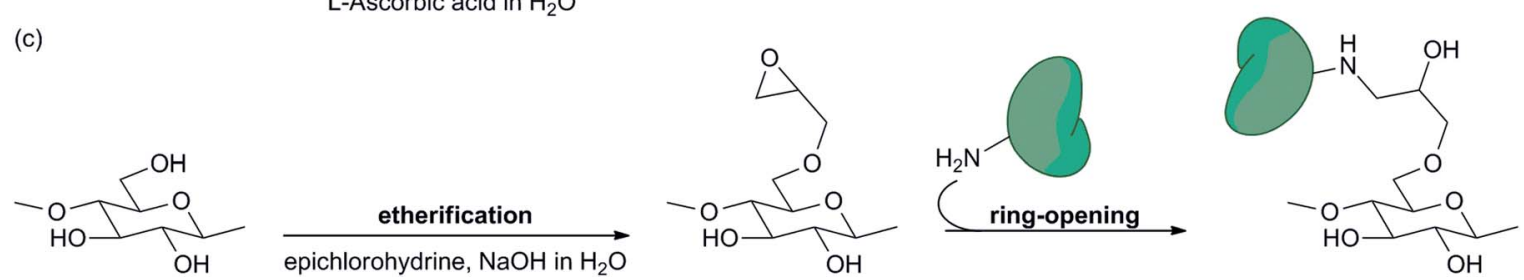

Fig. 23 Several ways to form secondary amine bonds.

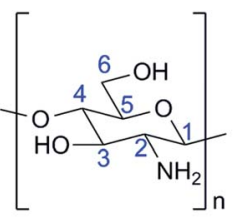

chitosan



carboxymethyl cellulose
Fig. 24 Structure of chitosan and carboxymethyl cellulose.

Cellulose has indeed lots of appealing properties such as large bioavailability, good biodegradability, biocompatibility and sustainability. This is the most important skeletal component in plants and guarantees their proper growth and structural integrity. Among structural entities of cellulose, microfibrils are stiff but cellulose fibers are resilient, thereby illustrating the duality of the cellulose material. Its behavior towards water is dual too since cellulose swells but does not dissolve in water, hence enabling fluids to wick by capillary action with no need for any external power source. All of its features make cellulose an ideal structural engineering material and a grade one platform for point-of-care diagnostic devices.

The immobilization of biomolecules onto cellulose paper is a key step in the development of paper-based biosensing devices and bioactive papers in general. Many procedures exist and this article has reviewed and categorized the current strategies for the immobilization of biomolecules onto pure cellulose membranes. These methodologies are classified into three major families: (i) physical methods, wherein the biomolecule is retained onto the cellulose support through physical forces such as electrostatic, van der Waals, hydrophobic interactions and hydrogen bonding, (ii) biological or biochemical methods wherein the biomolecule is linked to the cellulose paper through biochemical affinity between two components (e.g. $\mathrm{Ni}^{2+}$ /His-tag, streptavidin/biotin, protein G/human IgG), and (iii) chemical methods, wherein covalent bonds maintain the biomolecule on the support. Each of these techniques displays specific benefits and drawbacks. The physical approach is the simplest, the fastest and the most cost-saving, but also the weakest way of immobilizing biomolecules onto cellulose. Bioaffinity attachment is certainly the most acute technique since it is site specific and therefore enables controlling orientation of the immobilized biomolecules. Nevertheless, such a method requires complex and expensive genetic engineering procedures. Finally, chemical bonding is the strongest way of immobilizing biomolecules onto cellulose, but potentially the most damaging for these biomolecules. In consequence, there is no universal method for biomolecule immobilization onto 
cellulose. For a given paper based biochip, each and every strategy can be considered and new ones will probably arise. The most appropriate methodology should be chosen considering the nature of biomolecule, device and sample, as well as the budget allocated.

In the paper-based biosensor development process, fabrication is not a major difficulty whereas design of these devices remains a challenge since the fluidic path plays a crucial part in the biosensing kinetics and effective sensitivity of the sensor. Another issue is the choice of the transducing system which has to deliver a signal free from the alien substances and additive interferences and to allow for quantitative measurements whenever possible. Finally, preservation is still a tough problem, especially in resource-limited settings. Biomolecules not only have to stay onto the sensor support (leakage prevention), but most importantly they have to stay active, even under harsh conditions such as elevated temperatures. There is therefore a growing need for thermally stable biosensing entities and stabilizing technologies. Once these issues are addressed, new paper-based multiplex bioassays could be widely spread and used for on-site detection in remote areas in the developing world, but also in developed countries in emergency situations, in emergency rooms, at home or in military settings.

\section{References}

1 A. Payen, C. R. Hebd. Seances Acad. Sci., 1838, 7, 1052-1056.

2 D. Klemm, B. Heublein, H.-P. Fink and A. Bohn, Angew. Chem., Int. Ed. Engl., 2005, 44, 3358-3393.

3 E. J. Kontturi, Surface chemistry of cellulose: from natural fibres to model surfaces, Technische Universiteit Eindhoven, 2005, pp. 1-145.

4 J. S. Han and J. S. Rowell, in Paper and Composites from Agrobased Resources, ed. R. M. Rowell, R. A. Young, and J. K. Rowell, CRC Press, 1996, pp. 83-134.

5 D. Klemm, F. Kramer, S. Moritz, T. Lindström, M. Ankerfors, D. Gray and A. Dorris, Angew. Chem., Int. Ed. Engl., 2011, 50, 5438-5466.

6 S. Kalia, B. S. Kaith and I. Kaur, Cellulose Fibers: Bio- and Nano-polymer Composites, Springer, Berlin, Heidelberg, 2011.

7 E. J. Maxwell, A. D. Mazzeo and G. M. Whitesides, MRS Bull., 2013, 38, 309-314.

8 J. Credou, H. Volland, J. Dano and T. Berthelot, J. Mater. Chem. B, 2013, 1, 3277-3286.

9 Materials Research Society, MRS Bull., 2013, 38, 294-352.

10 J. Maumené, Philos. Mag. Ser. 3., 1850, 36, 482-482.

11 G. Oliver, Lancet, 1883, 121, 139-140.

12 G. Oliver, Br. Med. J., 1883, 1, 765.

13 A. H. Gordon, A. J. P. Martin and R. L. M. Synge, in Proceedings of the Biochemical Society, Portland Press Ltd., 1943, pp. xiii-xiv.

14 R. Consden, A. H. Gordon and A. J. Martin, Biochem. J., 1944, 38, 224-232.

15 R. H. Müller and D. L. Clegg, Anal. Chem., 1949, 21, 1123-1125.

16 A. H. Free, E. C. Adams, M. Lou Kercher, H. M. Free and M. H. Cook, Clin. Chem., 1957, 3, 163-168.
17 R. Hawkes, E. Niday and J. Gordon, Anal. Biochem., 1982, 119, 142-147.

18 G. A. Posthuma-Trumpie, J. Korf and A. van Amerongen, Anal. Bioanal. Chem., 2009, 393, 569-582.

19 B. Ngom, Y. Guo, X. Wang and D. Bi, Anal. Bioanal. Chem., 2010, 397, 1113-1135.

20 R. C. Wong and H. Y. Tse, Lateral Flow Immunoassay, Humana Press, New York, NY, 2009.

21 R. W. Peeling and D. Mabey, Clin. Microbiol. Infect., 2010, 16, 1062-1069.

22 P. von Lode, Clin. Biochem., 2005, 38, 591-606.

23 J. Burstein and G. D. Braunstein, Early Pregnancy: Biology and Medicine, 1995, 1, 288-296.

24 T. Chard, Hum. Reprod., 1992, 7, 701-710.

25 A. W. Martinez, S. T. Phillips and G. M. Whitesides, Proc. Natl. Acad. Sci. U. S. A., 2008, 105, 19606-19611.

26 E. M. Fenton, M. R. Mascarenas, G. P. López and S. S. Sibbett, ACS Appl. Mater. Interfaces, 2009, 1, 124-129.

27 E. Njumbe Ediage, J. D. Di Mavungu, I. Y. Goryacheva, C. Van Peteghem and S. De Saeger, Anal. Bioanal. Chem., 2012, 403, 265-278.

28 L. Ge, J. Yan, X. Song, M. Yan, S. Ge and J. Yu, Biomaterials, 2012, 33, 1024-1031.

29 S. M. Z. Hossain, C. Ozimok, C. Sicard, S. D. Aguirre, M. M. Ali, Y. Li and J. D. Brennan, Anal. Bioanal. Chem., 2012, 403, 1567-1576.

30 X. Li, D. R. Ballerini and W. Shen, Biomicrofluidics, 2012, 6, 011301.

31 P. Lisowski and P. K. Zarzycki, Chromatographia, 2013, 76, 1201-1214.

32 K. Abe, K. Kotera, K. Suzuki and D. Citterio, Anal. Bioanal. Chem., 2010, 398, 885-893.

33 L. Ge, S. Wang, X. Song, S. Ge and J. Yu, Lab Chip, 2012, 12, 3150-3158.

34 SENTINEL: Bioactive Paper Network, http://www.bioactive paper.ca/index.php? module $=$ page $\& i d=4000$, accessed 31 January, 2014.

35 A. W. Martinez, S. T. Phillips, G. M. Whitesides and E. Carrilho, Anal. Chem., 2010, 82, 3-10.

$36 \mathrm{H}$. Kettler, K. White and S. Hawkes, Mapping the landscape of diagnostics for sexually transmitted infections: key findings and recommandations, World Health Organization, Geneva, Switzerland, 2004.

37 C.-M. Cheng, A. W. Martinez, J. Gong, C. R. Mace, S. T. Phillips, E. Carrilho, K. A. Mirica and G. M. Whitesides, Angew. Chem., Int. Ed. Engl., 2010, 49, 4771-4774.

38 J. Hu, S. Wang, L. Wang, F. Li, T. J. Lu and F. Xu, Biosens. Bioelectron., 2014, 54, 585-597.

39 R. S. J. Alkasir, M. Ornatska and S. Andreescu, Anal. Chem., 2012, 84, 9729-9737.

40 M. Zhang, L. Ge, S. Ge, M. Yan, J. Yu, J. Huang and S. Liu, Biosens. Bioelectron., 2013, 41, 544-550.

41 C. Sicard and J. D. Brennan, MRS Bull., 2013, 38, 331-334. 42 M. Vert, Y. Doi, K. Hellwich, M. Hess, P. Hodge, P. Kubisa, M. Rinaudo and F. Schué, Pure Appl. Chem., 2012, 84, 377410. 
43 P. D. D. Klemm and P. D. T. Schmauder, Hans-Peter Heinze, in Biopolymers, Vol. 6 Polysaccharides II: Polysaccharides from Eukaryotes, ed. E. Vandamme, S. De Baets and A. Steinbüchel, Wiley-Blackwell, 2002, pp. 275-287.

44 P. Zugenmaier, Prog. Polym. Sci., 2001, 26, 1341-1417.

45 N. L. Ahrenstedt, Surface Modification of Cellulose Materials, School of Biotechnology Royal Institute of Technology, Stockholm, 2007, pp. 1-50.

46 S. Kalia, A. Dufresne, B. M. Cherian, B. S. Kaith, L. Avérous, J. Njuguna and E. Nassiopoulos, Int. J. Polym. Sci., 2011, 2011, 1-35.

47 D. Roy, M. Semsarilar, J. T. Guthrie and S. Perrier, Chem. Soc. Rev., 2009, 38, 2046-2064.

48 T. Zimmermann, E. Pöhler and T. Geiger, Adv. Eng. Mater., 2004, 6, 754-761.

49 N. Gierlinger and M. Schwanninger, Spectroscopy, 2007, 21, 69-89.

50 S. Wang, S. Lee and Q. Cheng,in Cellulose: Structure and Properties, Derivatives and Industrial Uses, ed. A. Lejeune and T. Deprez, 2010, pp. 459-500.

51 R. L. Crawford, Lignin biodegradation and transformation, John Wiley \& Sons Inc, New York, NY, USA, 1981.

52 M. Chabannes, K. Ruel, A. Yoshinaga, B. Chabbert, A. Jauneau, J. P. Joseleau and A. M. Boudet, Plant J., 2001, 28, 271-282.

53 D. Mohnen, Curr. Opin. Plant. Biol., 2008, 11, 266277.

54 H. König, L. Li and J. Fröhlich, Appl. Microbiol. Biotechnol., 2013, 97, 7943-7962.

55 R. Koroiva, C. W. O. Souza, D. Toyama, F. Henrique-Silva and a. a. Fonseca-Gessner, Genet. Mol. Res., 2013, 12, 3421-3434.

56 V. V. Zverlov, W. Höll and W. H. Schwarz, Int. Biodeterior. Biodegrad., 2003, 51, 175-179.

57 L. Zhu, Q. Wu, J. Dai, S. Zhang and F. Wei, Proc. Natl. Acad. Sci. U. S. A., 2011, 108, 17714-17719.

58 A. Michaelsen, F. Pinzari, N. Barbabietola and G. Piñar, Int. Biodeterior. Biodegrad., 2013, 84, 333-341.

59 M. Zotti, a. Ferroni and P. Calvini, Int. Biodeterior. Biodegrad., 2008, 62, 186-194.

60 F. Pinzari, G. Pasquariello and A. De Mico, Macromol. Symp., 2006, 238, 57-66.

61 M. C. Area and H. Cheradame, BioResources, 2011, 6, 53075337.

62 M. Mutwil, S. Debolt and S. Persson, Curr. Opin. Plant Biol., 2008, 11, 252-257.

63 Modulus of Elasticity - Young Modulus for some common Materials, http://www.engineeringtoolbox.com/youngmodulus-d_417.html.

64 Concrete Properties, http:/www.engineeringtoolbox.com/ concrete-properties-d_1223.html.

65 E. Malmström and A. Carlmark, Polym. Chem., 2012, 3, 1702-1713.

66 P.-A. Faugeras, P.-H. Elchinger, F. Brouillette, D. Montplaisir and R. Zerrouki, Green Chem., 2012, 14, 598-600.

67 D. Klemm, B. Philipp, T. Heinze, U. Heinze and W. Wagenknecht, Comprehensive Cellulose Chemistry
Volume 2 Functionalization of Cellulose, WILEY-VCH, Weinheim, 1998, vol. 2.

68 S. Kumar and P. Nahar, Talanta, 2007, 71, 1438-1440.

69 T. Heinze and T. Liebert, Prog. Polym. Sci., 2001, 26, 1689-1762.

70 S. Margutti, S. Vicini, N. Proietti, D. Capitani, G. Conio, E. Pedemonte and A. L. Segre, Polymer, 2002, 43, 6183-6194.

71 S. Wang, L. Ge, X. Song, M. Yan, S. Ge, J. Yu and F. Zeng, Analyst, 2012, 137, 3821-3827.

72 V. Weber, I. Linsberger, M. Ettenauer, F. Loth, M. Ho and D. Falkenhagen, Biomacromolecules, 2005, 6, 1864-1870.

73 H. Orelma, L.-S. Johansson, I. Filpponen, O. J. Rojas and J. Laine, Biomacromolecules, 2012, 13, 2802-2810.

74 H. Orelma, I. Filpponen, L.-S. Johansson, M. Osterberg, O. J. Rojas and J. Laine, Biointerphases, 2012, 7, 61.

75 K. Benhamou, A. Dufresne, A. Magnin, G. Mortha and H. Kaddami, Carbohydr. Polym., 2014, 99, 74-83.

76 S. Diekmann, G. Siegmund, A. Roecker and D. O. Klemm, Cellulose, 2003, 10, 53-63.

77 M. Granström, Cellulose Derivatives: Synthesis, Properties and Applications, Helsinki University Printing House, 2009, pp. 1-120.

78 G. E. Fridley, C. A. Holstein, S. B. Oza and P. Yager, MRS Bull., 2013, 38, 326-330.

79 H. Orelma, T. Teerinen, L.-S. Johansson, S. Holappa and J. Laine, Biomacromolecules, 2012, 13, 1051-1058.

80 C. Barba, D. Montané, M. Rinaudo and X. Farriol, Cellulose, 2002, 9, 319-326.

81 M. M. Ibrahim, A. Koschella, G. Kadry and T. Heinze, Carbohydr. Polym., 2013, 95, 414-420.

82 Y. Zhang, R. G. Carbonell and O. J. Rojas, Biomacromolecules, 2013, 14, 4161-4168.

83 M. Monier and A. M. a. El-Sokkary, Int. J. Biol. Macromol., 2012, 51, 18-24.

84 C. Corsaro, D. Mallamace, J. Lojewska, F. Mallamace, L. Pietronero and M. Missori, Sci. Rep., 2013, 3, 2896.

85 D. Klemm, B. Philipp, T. Heinze, U. Heinze and W. Wagenknecht, Comprehensive Cellulose Chemistry Volume 1 Fundamentals and Analytical Methods, WileyVCH, Weinheim, 1998.

86 M. Gericke, J. Trygg and P. Fardim, Chem. Rev., 2013, 113, 4812-4836.

87 R. J. Moon, A. Martini, J. Nairn, J. Simonsen and J. Youngblood, Chem. Soc. Rev., 2011, 40, 3941-3994.

88 M. A. Hubbe, R. A. Venditti and O. J. Rojas, BioResources, 2007, 2, 739-788.

89 H. Wondraczek, A. Kotiaho, P. Fardim and T. Heinze, Carbohydr. Polym., 2011, 83, 1048-1061.

90 P. J. Bracher, M. Gupta and G. M. Whitesides, Soft Matter, 2010, 4303-4309.

$91 \mathrm{H}$. Virtanen, H. Orelma, T. Erho and M. Smolander, Process Biochem., 2012, 47, 1496-1502.

92 S. Aikio, S. Grönqvist, L. Hakola, E. Hurme, S. Jussila, O.-V. Kaukoniemi, H. Kopola, M. Känsäkoski, M. Leinonen, S. Lippo, R. Mahlberg, S. Peltonen, P. Qvintus-Leino, T. Rajamäki, A.-C. Ritschkoff, M. Smolander, J. Vartiainen, L. Viikari and M. Vilkman, Bioactive paper and fibre products: Patent and literary survey, 2006. 
93 F. Kong and Y. F. Hu, Anal. Bioanal. Chem., 2012, 403, 7-13. 94 R. Pelton, Trends Anal. Chem., 2009, 28, 925-942.

95 D. D. Liana, B. Raguse, J. J. Gooding and E. Chow, Sensors, 2012, 12, 11505-11526.

96 H. Anany, W. Chen, R. Pelton and M. W. Griffiths, Appl. Environ. Microbiol., 2011, 77, 6379-6387.

97 S. M. Z. Hossain, R. E. Luckham, M. J. McFadden and J. D. Brennan, Anal. Chem., 2009, 81, 9055-9064.

98 M. Vaher and M. Kaljurand, Anal. Bioanal. Chem., 2012, 404, 627-633.

99 A.W. Martinez, S. T. Phillips, M. J. Butte and G. M. Whitesides, Angew. Chem., Int. Ed. Engl., 2007, 46, 1318-1320.

100 T. R. J. Holford, F. Davis and S. P. J. Higson, Biosens. Bioelectron., 2011, 34, 12-24.

101 A. H. Peruski and L. F. Peruski, Clin. Vaccine Immunol., 2003, 10, 506-513.

102 S. T. Phillips and G. G. Lewis, MRS Bull., 2013, 38, 315-319.

103 E. Carrilho, S. T. Phillips, S. J. Vella, A. W. Martinez and G. M. Whitesides, Anal. Chem., 2009, 81, 5990-5998.

104 E. Carrilho, A. W. Martinez and G. M. Whitesides, Anal. Chem., 2009, 81, 7091-7095.

105 S. Wang, L. Ge, X. Song, J. Yu, S. Ge, J. Huang and F. Zeng, Biosens. Bioelectron., 2012, 31, 212-218.

106 T. Songjaroen, W. Dungchai, O. Chailapakul and W. Laiwattanapaisal, Talanta, 2011, 85, 2587-2593.

107 A. Määttänen, U. Vanamo, P. Ihalainen, P. Pulkkinen, H. Tenhu, J. Bobacka and J. Peltonen, Sens. Actuators, B, 2012, 177, 153-162.

108 A. V. Govindarajan, S. Ramachandran, G. D. Vigil, P. Yager and K. F. Böhringer, Lab Chip, 2012, 12, 174-181.

109 L. Lafleur, D. Stevens, K. McKenzie, S. Ramachandran, P. Spicar-Mihalic, M. Singhal, A. Arjyal, J. Osborn, P. Kauffman, P. Yager and B. Lutz, Lab Chip, 2012, 12, 1119-1127.

110 Millistak+ HC Filter Devices (with RW01); MSDS No. M114480, Millipore Corporation, Billerica, MA, 2008.

111 Nitrocellulose Membrane Filters; MSDS No. 00000100SDS, Millipore Corporation, Billerica, MA, 2011.

112 F. Rusmini, Z. Zhong and J. Feijen, Biomacromolecules, 2007, 8, 1775-1789.

113 A. Sassolas, L. J. Blum and B. D. Leca-Bouvier, Biotechnol. Adv., 2012, 30, 489-511.

114 R. DiCosimo, J. McAuliffe, A. J. Poulose and G. Bohlmann, Chem. Soc. Rev., 2013, 42, 6437-6474.

115 A. Fishman, I. Levy, U. Cogan and O. Shoseyov, J. Mol. Catal. B: Enzym., 2002, 18, 121-131.

116 A. Liese and L. Hilterhaus, Chem. Soc. Rev., 2013, 42, 62366249.

117 F. Secundo, Chem. Soc. Rev., 2013, 42, 6250-6261.

118 Millipore, Rapid Lateral Flow Test Strips Considerations for Product Development, Millipore Corporation, Billerica, MA, 2008.

119 M. M. F. Choi, Microchim. Acta, 2004, 148, 107-132.

120 S. N. Di Risio, Fundamental investigation of inkjet deposition and physical immobilization of horseradish peroxidase on cellulosic substrates, University of Toronto, 2009, pp. 1-200.
121 M. M. M. Elnashar, in Biotechnology of Biopolymers, ed. M. M. M. Elnashar, InTech, Rijeka, Croatia, 2011, pp. 3-33.

122 X. Y. Liu, C. M. Cheng, A. W. Martinez, K. A. Mirica, X. J. Li, S. T. Phillips, M. Mascareñas and G. M. Whitesides, in MEMS 2011, IEEE, Cancun, MEXICO, 2011, pp. 75-78.

123 S.-N. Tan, L. Ge, H. Y. Tan, W. K. Loke, G. Jinrong and W. Wang, Anal. Chem., 2012, 84, 10071-10076.

124 J. Yu, L. Ge, J. Huang, S. Wang and S. Ge, Lab Chip, 2011, 11, 1286-1291.

125 J. Yu, S. Wang, L. Ge and S. Ge, Biosens. Bioelectron., 2011, 26, 3284-3289.

126 G. Zhou, X. Mao and D. Juncker, Anal. Chem., 2012, 84, 7736-7743.

127 E. Halder, D. K. Chattoraj and K. P. Das, Biopolymers, 2005, 77, 286-295.

128 P. Jarujamrus, J. Tian, X. Li, A. Siripinyanond, J. Shiowatana and W. Shen, Analyst, 2012, 137, 2205-2210.

129 J. Tian, P. Jarujamrus, L. Li, M. Li and W. Shen, ACS Appl. Mater. Interfaces, 2012, 4, 6573-6578.

130 M. Al-Tamimi, W. Shen, R. Zeineddine, H. Tran and G. Garnier, Anal. Chem., 2012, 84, 1661-1668.

131 J. Su, M. Al-Tamimi and G. Garnier, Cellulose, 2012, 19, 1749-1758.

132 G. Hussack, Y. Luo, L. Veldhuis, J. C. Hall, J. Tanha and R. Mackenzie, Sensors, 2009, 9, 5351-5367.

133 A. Makky, T. Berthelot, C. Feraudet-Tarisse, H. Volland, P. Viel and J. Polesel-Maris, Sens. Actuators, B, 2012, 162, 269-277.

134 P. Peng, L. Summers, A. Rodriguez and G. Garnier, Colloids Surf., B, 2011, 88, 271-278.

135 S. Su, M. M. Ali, C. D. M. Filipe, Y. Li and R. Pelton, Biomacromolecules, 2008, 9, 935-941.

136 D. Brady and J. Jordaan, Biotechnol. Lett., 2009, 31, 16391650.

137 Z. Zhao, J. Tian, Z. Wu, J. Liu, D. Zhao, W. Shen and L. He, J. Mater. Chem. B, 2013, 1, 4719-4722.

138 Y. Xiao and T.-S. Chung, J. Membr. Sci., 2007, 290, 78-85.

139 P. a. Larsson, S. G. Puttaswamaiah, C. Ly, A. Vanerek, J. C. Hall and F. Drolet, Colloids Surf., B, 2013, 101, 205-209.

140 Thermo Scientific, Innovative devices for secure sample dialysis, Thermo Fisher Scientific Inc., Rockford, lL, 2013.

141 Thermo Scientific, Dialysis Methods for Protein Research, http://www.piercenet.com/method/dialysis-methodsprotein-research, accessed 27 September, 2013.

142 H. A. Krässig, in Cellulose, structure, accessibility and reactivity, Gordon and Breach Publishers, Philadelphia, PA, 1993, vol. 32.

143 I. Levy and O. Shoseyov, Biotechnol. Adv., 2002, 20, 191-213. 144 K. Terpe, Appl. Microbiol. Biotechnol., 2003, 60, 523-533.

145 J. Nahálka and P. Gemeiner, J. Biotechnol., 2006, 123, 478482 .

146 N. Sugimoto, K. Igarashi and M. Samejima, Protein Expr. Purif., 2012, 82, 290-296.

147 S. Hwang, J. Ahn, S. Lee, T. G. Lee, S. Haam, K. Lee, I.-S. Ahn and J.-K. Jung, Biotechnol. Lett., 2004, 26, 603-605.

148 H. Park, J. Ahn, J. Lee, H. Lee, C. Kim, J.-K. Jung, H. Lee and E. G. Lee, Int. J. Mol. Sci., 2012, 13, 358-368. 
149 W. Lewis, E. Keshavarz-Moore, J. Windust, D. Bushell and N. Parry, Biotechnol. Bioeng., 2006, 94, 625-632.

150 Y. Cao, Q. Zhang, C. Wang, Y. Zhu and G. Bai, J. Chromatogr. A, 2007, 1149, 228-235.

151 G. Hussack, B. M. Grohs, K. C. Almquist, M. D. McLean, R. Ghosh and J. C. Hall, J. Agric. Food Chem., 2010, 58, 3451-3459.

152 K. D. Le, N. R. Gilkes, D. G. Kilburn, R. C. Miller, J. N. Saddler and R. A. J. Warren, Enzyme Microb. Technol., 1994, 16, 496-500.

153 S. Daunert, L. G. Bachas, V. Schauer-Vukasinovic, K. J. Gregory, G. Schrift and S. Deo, Colloids Surf., B, 2007, 58, 20-27.

154 E. Fasoli, Y. R. Reyes, O. M. Guzman, A. Rosado, V. R. Cruz, A. Borges, E. Martinez and V. Bansal, J. Chromatogr. B: Anal. Technol. Biomed. Life Sci., 2013, 930, 13-21.

155 R. Y. Tam, M. J. Cooke and M. S. Shoichet, J. Mater. Chem., 2012, 22, 19402-19411.

156 S. A. Yankofsky, R. Gurevitch, A. Niv, G. Cohen and L. Goldstein, Anal. Biochem., 1981, 118, 307-314.

157 V. G. Janolino and H. E. Swaisgood, J. Food Biochem., 2007, 26, 119-129.

158 S. Jung, B. Angerer, F. Löscher, S. Niehren, J. Winkle and S. Seeger, Chembiochem, 2006, 7, 900-903.

159 J. Huang, I. Ichinose and T. Kunitake, Angew. Chem., Int. Ed. Engl., 2006, 45, 2883-2886.

160 G. T. Hermanson, Bioconjugate techniques, Academic Press, London, 2008.

161 J. Turková, J. Chromatogr. B, 1999, 722, 11-31.

162 T. Barroso, M. Temtem, A. Hussain, A. Aguiar-Ricardo and A. C. a. Roque, J. Membr. Sci., 2010, 348, 224-230.

163 V. Gaberc-Porekar and V. Menart, J. Biochem. Biophys. Methods, 2001, 49, 335-360.

164 Thermo Scientific, His-tagged Proteins, http:// www.piercenet.com/browse.cfm?fldID $=1470 \mathrm{D} 72 \mathrm{~F}-469 \mathrm{~A}-$ 424B-90F7-2EDBCFBD33FC, accessed 27 September, 2013.

165 J. A. Bornhorst and J. J. Falke, Methods Enzymol., 2010, 326, 245-254.

166 C. Ley, D. Holtmann, K.-M. Mangold and J. Schrader, Colloids Surf., B, 2011, 88, 539-551.
167 J. Wang, B. Yiu, J. Obermeyer, C. D. M. Filipe, J. D. Brennan and R. Pelton, Biomacromolecules, 2012, 13, 559-564.

168 P. Jonkheijm, D. Weinrich, H. Schröder, C. M. Niemeyer and H. Waldmann, Angew. Chem., Int. Ed. Engl., 2008, 47, 9618-9647.

169 R. a. Sheldon and S. van Pelt, Chem. Soc. Rev., 2013, 42, 6223-6235.

170 M. Ornatska, E. Sharpe, D. Andreescu and S. Andreescu, Anal. Chem., 2011, 83, 4273-4280.

171 W. Liu, C. L. Cassano, X. Xu and Z. H. Fan, Anal. Chem., 2013, 85, 10270-10276.

172 H. Orelma, I. Filpponen, L.-S. Johansson, J. Laine and O. J. Rojas, Biomacromolecules, 2011, 12, 43114318.

173 S. Arola, T. Tammelin, H. Setälä, A. Tullila and M. B. Linder, Biomacromolecules, 2012, 13, 594-603.

174 R. Villalonga, A. Fujii, H. Shinohara, S. Tachibana and Y. Asano, Sens. Actuators, B, 2008, 129, 195-199.

175 U. Bora, P. Sharma, K. Kannan and P. Nahar, J. Biotechnol., 2006, 126, 220-229.

176 U. Bora, K. Kannan and P. Nahar, J. Membr. Sci., 2005, 250, 215-222.

177 M. Erdtmann, R. Keller and H. Baumann, Biomaterials, 1994, 15, 1043-1048.

178 A. Yu, J. Shang, F. Cheng, B. A. Paik, J. M. Kaplan, R. B. Andrade and D. M. Ratner, Langmuir, 2012, 28, 11265-11273.

179 V. Kuzmenko, S. Sämfors, D. Hägg and P. Gatenholm, Mater. Sci. Eng., C, 2013, 33, 4599-4607.

180 Y. Wang, S. Wang, S. Ge, S. Wang, M. Yan, D. Zang and J. Yu, Anal. Methods, 2013, 5, 1328-1336.

181 A. C. Araújo, Y. Song, J. Lundeberg, P. L. Ståhl and H. Brumer, Anal. Chem., 2012, 84, 3311-3317.

182 J. Martínez Urreaga and M. U. de la Orden, Eur. Polym. J., 2006, 42, 2606-2616.

183 J. Malešič, J. Kolar, M. Strlič, D. Kočar, D. Fromageot, J. Lemaire and O. Haillant, Polym. Degrad. Stab., 2005, 89, 64-69.

184 A. Aied, Y. Zheng, A. Pandit and W. Wang, ACS Appl. Mater. Interfaces, 2012, 4, 826-831. 